\title{
Understanding the Intermodel Spread in Global-Mean Hydrological Sensitivity*
}

\author{
DAgMAR FläSCHNER, THORSTEN MAURITSEN, AND BJORn STEVENS
}

Max Planck Institute for Meteorology, Hamburg, Germany

(Manuscript received 14 May 2015, in final form 8 November 2015)

\begin{abstract}
This paper assesses intermodel spread in the slope of global-mean precipitation change $\Delta P$ with respect to surface temperature change. The ambiguous estimates in the literature for this slope are reconciled by analyzing four experiments from phase 5 of CMIP (CMIP5) and considering different definitions of the slope. The smallest intermodel spread (a factor of 1.5 between the highest and lowest estimate) is found when using a definition that disentangles temperature-independent precipitation changes (the adjustments) from the slope of the temperature-dependent precipitation response; here this slope is referred to as the hydrological sensitivity parameter $\eta$. The estimates herein show that $\eta$ is more robust than stated in most previous work. The authors demonstrate that adjustments and $\eta$ estimated from a steplike quadrupling $\mathrm{CO}_{2}$ experiment serve well to predict $\Delta P$ in a transient $\mathrm{CO}_{2}$ experiment. The magnitude of $\eta$ is smaller in the coupled oceanatmosphere quadrupling $\mathrm{CO}_{2}$ experiment than in the noncoupled atmosphere-only experiment. The offset in magnitude due to coupling suggests that intermodel spread may undersample uncertainty.

Also assessed are the relative contribution of $\eta$, the surface warming, and the adjustment on the spread in $\Delta P$ on different time scales. Intermodel variation of both $\eta$ and the adjustment govern the spread in $\Delta P$ in the years immediately after the abrupt forcing change. In equilibrium, the uncertainty in $\Delta P$ is dominated by uncertainty in the equilibrium surface temperature response. A kernel analysis reveals that intermodel spread in $\eta$ is dominated by intermodel spread in tropical lower tropospheric temperature and humidity changes and cloud changes.
\end{abstract}

\section{Introduction}

The intermodel spread in global-mean precipitation response appears to be substantial in simulations of global warming. To narrow this spread, it may be helpful to understand the slope of global-mean precipitation changes with respect to global-mean temperature. However, estimates of the intermodel spread in this slope vary from one study to another. To discern the origin of these differences, we reassess intermodel spread and the magnitude of the slope of global-mean precipitation change with global-mean surface warming in climate change experiments carried out as part of phase 5 of the Coupled Model Intercomparison Project (CMIP5). We further

\footnotetext{
* Supplemental information related to this paper is available at the Journals Online website: http://dx.doi.org/10.1175/JCLI-D-150351.s1.

Corresponding author address: Dagmar Fläschner, Atmosphere in the Earth System, Max Planck Institute for Meteorology, Bundesstraße 53, 20146 Hamburg, Germany.

E-mail: dagmar.flaeschner@mpimet.mpg.de
}

investigate the relative contributions of different processes to the spread in the simulated global-mean precipitation response. We only investigate global-mean precipitation changes in this study. For simplicity hereafter, when we mention precipitation or surface temperature, we refer to the global-mean quantities.

That changes in global-mean precipitation are constrained by the energetics of the atmosphere is well understood (e.g., Newell et al. 1975; Mitchell et al. 1987; Boer 1993; Allen and Ingram 2002; Held and Soden 2006; O'Gorman et al. 2012). Given this energetic constraint, it could be assumed that estimates of the slope of precipitation change with surface temperature change would be likewise constrained. However, the estimates of intermodel spread vary among studies, from the smallest spread of $1.82-2.70 \mathrm{~W} \mathrm{~m}^{-2} \mathrm{~K}^{-1}$ (a factor of 1.5 between the lowest and highest model estimates) in Andrews et al. (2009) to studies suggesting much larger intermodel spreads up to a factor of 3.3 for models participating in phase 3 of CMIP (CMIP3) and CMIP5 (Table 1). In addition to different estimates of intermodel spread, the ensemble-mean magnitude of the ratio of precipitation change with warming also differs across these model-based studies. 
TABLE 1. Comparison between the literature and this study for estimates of the slope of precipitation change with respect to surface temperature change; $\eta$ denotes the hydrological sensitivity parameter and $\eta_{a}$ the apparent hydrological sensitivity parameter. The absolute spread shows the lowest-highest model estimate $\left(\mathrm{W} \mathrm{m}^{-2} \mathrm{~K}^{-1}\right.$, values in parentheses have the unit $\left.\% \mathrm{~K}^{-1}\right)$. The factor of spread is the approximate ratio between the lowest and highest model estimate. The dispersion (\%) is the ensemble standard deviation divided by the ensemble mean.

\begin{tabular}{|c|c|c|c|c|}
\hline Study & Definition of slope & Absolute spread & Factor of spread & Dispersion \\
\hline Held and Soden (2006) & $\eta_{a}$ & $(1-3)$ & 3 & - \\
\hline \multirow[t]{2}{*}{ Lambert and Webb (2008) } & $\eta$ & $1.3-3.2$ & 2.4 & - \\
\hline & & $(1.4-3.4)$ & 2.4 & - \\
\hline Andrews et al. (2009) & $\eta$ & $1.82-2.70$ & 1.5 & 11 \\
\hline Takahashi (2009) & $\eta$ & $1.50-3.13$ & 2.1 & 19 \\
\hline Lambert and Allen (2009) & $\eta$ & $0.84-1.97$ & 2.3 & 27 \\
\hline Frieler et al. (2011) & $\eta$ & - & - & 24 \\
\hline Previdi (2010) & $\eta_{a}$ & $(0.71-2.37)$ & 3.3 & 31 \\
\hline Pendergrass and Hartmann (2014) & $\eta_{a}$ & $0.7-1.9$ & 2.7 & 27 \\
\hline \multirow[t]{2}{*}{ This study (from abrupt $4 x \mathrm{xO} 2$ ) } & $\eta$ & $1.85-2.73$ & 1.5 & 11 \\
\hline & & $(2.1-3.3)$ & 1.6 & 11 \\
\hline
\end{tabular}

General circulation models are an indispensable tool for studying and predicting precipitation changes. However, the different estimates of the slope of globalmean precipitation change may raise doubts for the models' abilities to correctly predict global-mean precipitation changes with global warming. Understanding the reasons for the different model-based estimates in the literature is important to judge how confident one can be in the predictions of precipitation change. This insight may eventually help to improve the representation of physical processes in the models and eventually the prediction of precipitation change with global warming.

Physical and methodological issues complicate the interpretation of estimates of the precipitation response to warming in the literature. First, climate change experiments with different degrees of idealization-from very idealized $\mathrm{CO}_{2}$-step configurations to transient scenarios including multiple forcing agents-were analyzed. Second, the authors defined the slope of precipitation change with respect to surface temperature change in different ways, but described it using the same term: hydrological sensitivity.

In some studies the term hydrological sensitivity is used to denote the ratio of global-mean precipitation change to the corresponding global-mean surface temperature change, where the changes were estimated as the differences between the perturbed and control mean states (e.g., Held and Soden 2006; Bala et al. 2008; Previdi 2010; Pendergrass and Hartmann 2014). Other studies incorporate the expectation that precipitation not only changes proportionally with surface temperature, but also adjusts directly to forcing agents. For instance, Allen and Ingram (2002) and other studies (e.g., Lambert and Webb 2008; Andrews et al. 2009) express the global-mean precipitation changes $\Delta P$ as a linear function of the surface temperature changes $\Delta T_{s}$ following

$$
\Delta P=\eta \Delta T_{s}+A
$$

where $\eta$ is the proportionality factor between $\Delta P$ and $\Delta T_{s}$, and $A$ is an adjustment term that measures the direct response of precipitation to forcing, independent of any eventual surface temperature change. If, for example, the $\mathrm{CO}_{2}$ concentration in the atmosphere is abruptly increased, the atmosphere is directly cooled less via the increased absorption of longwave radiation from $\mathrm{CO}_{2}$ (Ramanathan 1981). To balance this reduction in radiative cooling, the atmosphere reacts rapidly by reducing a heating source, the precipitation (e.g., Allen and Ingram 2002; Andrews et al. 2009). Rising temperatures due to the forcing then lead to more atmospheric cooling. Precipitation is thus initially suppressed by abruptly increasing levels of $\mathrm{CO}_{2}$, but increases proportionally to surface temperature warming when the forcing is held constant. The proportionality factor $\eta$ of precipitation change with surface temperature change has formerly been referred to as differential hydrological sensitivity but also, ambiguously, as hydrological sensitivity.

A more precise terminology for precipitation changes with temperature changes would be helpful. For the remainder of this work we will adopt a terminology (illustrated in Fig. 1) that is analogous to the well-defined framework of equilibrium climate sensitivity (ECS).

In the ECS framework (e.g., Sherwood et al. 2015), an external forcing $F$ causes a radiative imbalance at the top of the atmosphere $\Delta R^{\mathrm{TOA}}$ that arises from the direct radiative forcing as well as adjustments of atmospheric properties without any change in the global-mean surface temperature (e.g., clouds). The surface temperature 


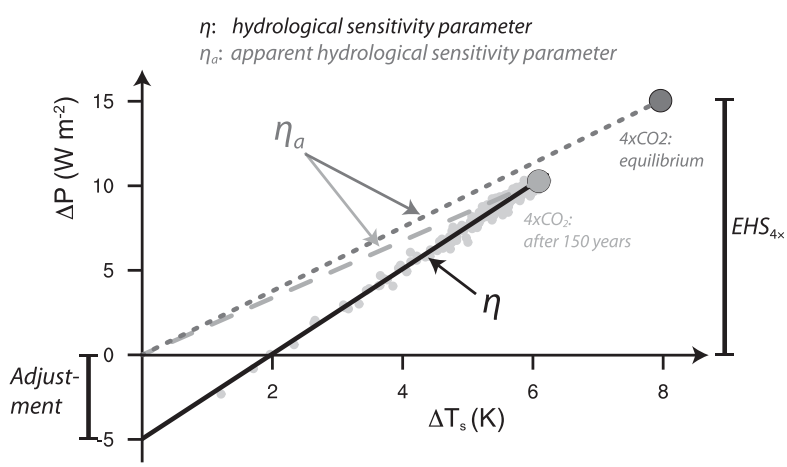

FIG. 1. Illustration of the terminology for precipitation change with surface temperature change adopted in this work, by the example of abrupt4xCO2 data from IPSL-CM5A-LR. The hydrological sensitivity parameter $\eta$ is the slope of the global-mean precipitation response with respect to surface temperature change when explicitly taking into account the rapid "adjustment" of precipitation due to forcing agents. The apparent hydrological sensitivity parameter $\eta_{a}$ is given by the slope of global time-mean responses without accounting for rapid precipitation adjustments. The equilibrium precipitation change due to a quadrupling of $\mathrm{CO}_{2}$ is denoted as equilibrium hydrological sensitivity at $4 \times \mathrm{CO}_{2}$ $\left(\mathrm{EHS}_{4 \times}\right)$. Small circles signify annual global means, and large circles the endpoint and equilibrium mean.

responds to the radiative imbalance according to $\Delta R^{\mathrm{TOA}}=\lambda \Delta T_{s}+F$ (e.g., Gregory et al. 2004) until a new equilibrium is reached. The slope $\lambda$ is called the climate feedback parameter and the surface warming in equilibrium due to a doubling of $\mathrm{CO}_{2}$ is called equilibrium climate sensitivity.

In analogy, for precipitation changes we will hereafter refer to the amount of global-mean precipitation change in equilibrium due to a doubling of $\mathrm{CO}_{2}$ as equilibrium hydrological sensitivity (EHS) and to $\eta$, the slope of temperature-dependent precipitation change, as the hydrological sensitivity parameter. In contrast to $\lambda, \eta$ is not a feedback parameter because $\Delta P$ does not feed back on $\Delta T_{s}$. The slope of total precipitation change to total surface temperature change will be referred to as the apparent hydrological sensitivity parameter $\eta_{a}$, where "apparent" alludes to the fact that $\eta_{a}$ is what one might observe, but is sensitive to the nature of the forcing. On the contrary, we prefer to think of $\eta$ as a more characteristic quantity that does not depend on the specifics of the forcing agent or the details of the surface warming (Andrews et al. 2009; Bala et al. 2010; Andrews et al. 2010; Kvalevåg et al. 2013). However, if $A$ is not known a priori, then $\eta$ can only be estimated in steplike forcing experiments.

The aim of this work is to gain more insight into reasons for the intermodel spread in the hydrological sensitivity. In light of the terminological ambiguity discussed above, we aim to investigate the term hydrological sensitivity for both the previous definition and our current terminology. First, we reassess the intermodel spread in the slope of precipitation change with surface temperature change ( $\eta$ and $\eta_{a}$ ) in four CMIP5 experiments, compare our estimates with the literature, and provide physical explanations for differences among estimates. We discuss how the value and intermodel spread depend on the definition and on the analyzed climate change experiment in a set of CMIP5 models (section 3) as well as the applicability of $\eta$ and $A$ derived from idealized steplike $\mathrm{CO}_{2}$-forcing experiment to a transient $\mathrm{CO}_{2}$ experiment (section 4).

In the second part of this study, we discuss the intermodel spread in global-mean precipitation response among the different CMIP5 models in an idealized experiment with abruptly quadrupled $\mathrm{CO}_{2}$ concentration (section 5). We assess how the three factors from Eq. (1) $\left(\eta, \Delta T_{s}\right.$, and $A$ ) contribute to the spread in the equilibrium precipitation response, following the illustrative approach of Hawkins and Sutton (2009). Previdi (2010) and O'Gorman et al. (2012) investigated reasons for intermodel spread in the slope of precipitation change with the radiative kernel method (Soden et al. 2008), finding that the spread from clouds dominates over the spread from temperature and water vapor changes. Takahashi (2009) proposes that the intermodel spread in the slope is caused by scatter in the shortwave absorption among models. Pendergrass and Hartmann (2014) show that temperature and water vapor profiles change differently and thus cause differences in the atmospheric heat budget. To gain more insight into causes for intermodel spread in $\eta$ and $A$, we employ the methodology as in Previdi (2010), but use newer radiative kernels (radiative flux perturbations due to a unit change in atmospheric state variable) to decompose the atmospheric heat budget into contributions from $\mathrm{CO}_{2}$, temperature, water vapor, and clouds.

\section{Experiments and methods}

\section{a. Experiments}

We investigate four CMIP5 experiments (Taylor et al. 2012), in which the atmospheric heat budgets are perturbed in distinct ways. Coupled ocean-atmosphere (piControl, historical, 1pctCO2, and abrupt4xCO2) and noncoupled atmosphere-only experiments (amip and amip4K) are analyzed. To interpret our findings we also analyze other specialized experiments (amipFuture; see also sstClim and sstClim4xCO2 in the supplementary material).

The historical simulation starts from preindustrial control conditions (piControl experiment) but with prescribed transient historical forcings. Transient 
forcings include well-mixed greenhouse gases and natural and anthropogenic aerosols as well as land-use, solar, and orbital forcings. Although recommended input for most of these forcings was provided, modeling groups were free to specify aspects such as the aerosol forcing.

The radiative forcing is less ambiguously defined in the more idealized CMIP5 experiments. In the $1 \mathrm{pctCO} 2$ experiment the forcing consists of a gradual $1 \% \mathrm{yr}^{-1}$ increase of the $\mathrm{CO}_{2}$ concentration, yielding a near-linear increase in radiative forcing. The $\mathrm{CO}_{2}$ concentration doubles after 70 years and quadruples after 140 years. In the abrupt4xCO2 experiment, the preindustrial $\mathrm{CO}_{2}$ concentration is abruptly quadrupled with respect to piControl and then held constant for the remainder of the simulation. The CMIP5 experiment protocol calls for at least 150 years of simulation length for experiments with coupled models. If modeling centers provided longer time series, all available monthly mean values were included in the analysis. We selected models for which the abrupt $4 \mathrm{xCO} 2$ experiment was available. Only one ensemble member of each model (r1i1p1) is included in the analysis. The noncoupled amip and amip4K experiments are part of the Cloud Feedback Model Intercomparison Project (Bony et al. 2011) where models are driven by prescribed sea surface temperatures for the period 1979-2008 and the corresponding forcing agents. In amip4K, the sea surface temperatures are uniformly raised by $4 \mathrm{~K}$ but all other boundary conditions remain as in the amip experiment.

\section{b. Calculation methods}

Two common methods exist to calculate $\eta$ : the regression method (e.g., Gregory et al. 2004; Andrews et al. 2009; Lambert and Webb 2008) and the fixed-SST method (Hansen et al. 2005; Bala et al. 2010; Andrews et al. 2010; Kvalevåg et al. 2013). For the abrupt4xCO2 experiment we perform an ordinary least squares regression between annual global-mean $\Delta T_{s}$ and $\Delta P$, where $\eta$ is given by the slope and $A$ by the $y$ intercept. For the amip4K experiment, we compute $\Delta P$ and $\Delta T_{s}$ as the global and time-mean differences over the period of 1979-2008 between amip4K and amip. Because the adjustment $A$ is zero in amip4K, $\eta$ is given directly as the ratio $\Delta P / \Delta T_{s}$.

The apparent hydrological sensitivity parameter has usually been calculated by subtracting global time averages over the last years of the perturbed experiment from a climatological mean of the control state or alternatively of the beginning years of the perturbed climate change experiment. We follow this approach for the abrupt $4 \mathrm{xCO} 2$ experiment, and estimate $\eta_{a}$ for two different time means. The endpoint mean refers to the global time average over the last 10 years of a model's simulation. The equilibrium mean is discussed here because the endpoint mean is not representative of equilibrium conditions, as the equilibration time scale in coupled models is much greater than the typical 150-yr simulation length. To estimate the equilibrium hydrological sensitivity for a quadrupling of $\mathrm{CO}_{2}\left(\mathrm{EHS}_{4 \times}\right)$, we follow the Gregory method (Gregory et al. 2004) and extrapolate the top-of-atmosphere (TOA) radiative flux imbalance toward equilibrium, finding the equilibrium climate sensitivity for a $4 \times \mathrm{CO}_{2}$ forcing $\left(\mathrm{ECS}_{4 \times}\right)$. Together with $\eta$ and $A$, the $\mathrm{EHS}_{4 \times}$ is determined by Eq. (1). Unless otherwise noted, we calculate $\eta_{a}$ for both the historical and $1 \mathrm{pctCO} 2$ experiments as the slope from the regression of annual-mean $\Delta T_{s}$ and $\Delta P$. We choose this method because it yields the general trend of precipitation evolution with surface temperature for the transient forcing experiment. This method is shown to be superior to the method of differencing time averages for estimating linear trends (Barnes and Barnes 2015). Note that transient forcing simulations do not readily allow one to separate the adjustment.

\section{The slope of precipitation change with respect to surface temperature change in CMIP5 simulations}

Here we compare the slope of global-mean precipitation increase with respect to surface warming as found in four CMIP5 experiments and estimated according to the definitions in section 1 . The ensemblemean values and their intermodel spread of $\eta$ and $\eta_{a}$ are portrayed by Gaussian distributions (Fig. 2a). Individual model values are given in Table 2 . The spread is shown as the standard deviation across the ensemble (Fig. 2a) or in terms of the dispersion (Fig. 2b), which is the standard deviation normalized by the ensemble mean. Because the dispersion provides a measure of the relative spread among models, it is more indicative of the interexperiment spread than the standard deviation. The smaller the dispersion, the smaller is the relative intermodel spread.

First we examine how the magnitude and spread depend on the definition of the slope. The dependence on the definition can only be tested with the abrupt $4 \mathrm{xCO} 2$ experiment. It is well understood that $\eta$ is greater than $\eta_{a}$ because the fast precipitation adjustment to an increase in $\mathrm{CO}_{2}$ is negative (e.g., Allen and Ingram 2002; Andrews et al. 2009; Bala et al. 2010). We show that the choice of $\eta$ or $\eta_{a}$ to characterize the hydrological sensitivity also strongly influences the spread of the slope (Fig. 2b). The dispersion, and thus the relative intermodel spread, is smallest for $\eta(10.7 \%)$ and larger 


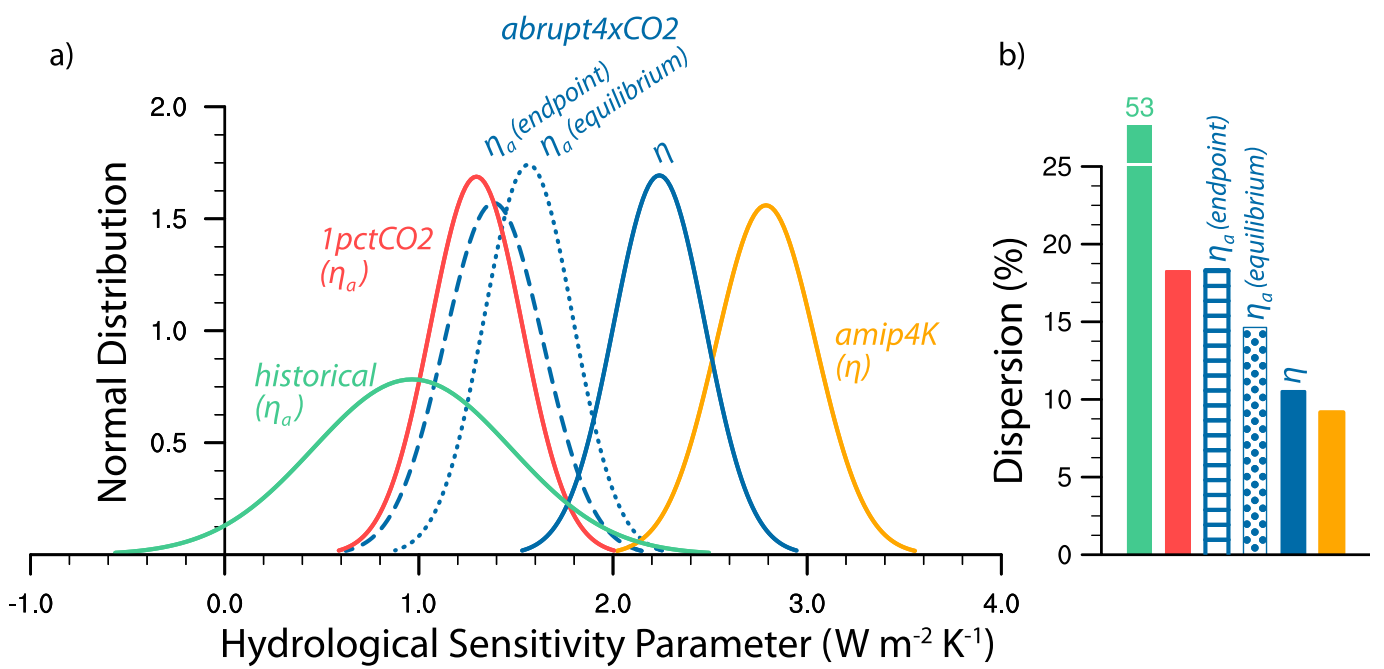

FIG. 2. Comparison of the slope of precipitation change with respect to surface temperature change for different definitions of the slope and different CMIP5 experiments. (a) The spread is shown as Gaussian curves, as given by the ensemble mean and standard deviation of $\eta$ and $\eta_{a}$. (b) The ensemble standard deviation is scaled by the ensemble mean to yield the dispersion. Table 2 lists the parameter values for all models.

for the two $\eta_{a}$ estimates. The smaller spread in $\eta$ is simply explained by the fact that the spread of the slope is explicitly separated from the spread of the adjustment. Estimating the slope via the definition of $\eta_{a}$ reveals that its magnitude and spread are sensitive to the surface warming, and thus time. When $\eta_{a}$ is computed at equilibrium conditions (greater surface warming), the spread from the adjustment loses its impact on the spread of the slope relative to endpoint conditions (smaller dispersion of $14.6 \%$ versus $18.2 \%)$. Not being influenced by the adjustment, the definition of $\eta$ yields a more precise estimate for the increase of precipitation with surface warming (2.24 \pm $0.24 \mathrm{~W} \mathrm{~m}^{-2} \mathrm{~K}^{-1}$; error is given as one intermodel standard deviation).

The interexperiment differences in magnitude and spread of the slope depend on the experiment configuration. For the idealized steplike warming experiment (amip4K), the spread in $\eta$ is similarly small (dispersion of $9.3 \%$ ) as for abrupt $4 \mathrm{xCO} 2$. That the magnitude of $\eta$ is higher in amip4K $\left(2.79 \pm 0.26 \mathrm{~W} \mathrm{~m}^{-2} \mathrm{~K}^{-1}\right)$ as compared to abrupt $4 \mathrm{xCO} 2$ is unexpected; the usage of the same definition should yield similar values if $\eta$ is a characteristic quantity for the evolution of the temperaturedependent $\Delta P$. Possible reasons for differences are discussed in more detail in section 6 .

For the transient experiments $(1 \mathrm{pctCO} 2$ and historical), the slope is, as explained above, suppressed by the effect of the adjustments. Here only $\eta_{a}$ can be estimated because the exact forcings for the individual models are unknown. The suppression is stronger in the historical simulation $\left(0.91 \pm 0.51 \mathrm{~W} \mathrm{~m}^{-2} \mathrm{~K}^{-1}\right)$. In addition to greenhouse gas forcings, absorbing aerosols (e.g., biomass burning and black carbon) reduce the precipitation increase (e.g., Andrews et al. 2010; Kvalevåg et al. 2013). Among the considered experiments, the spread is largest in the historical simulation (dispersion of $53 \%$ ), although it is calculated by the regression method, thereby yielding the trend of historical $\Delta P$ evolution with $\Delta T_{s}$. Estimates of $\eta_{a}$ have even greater spread when calculated using the endpoint method (Table 3) because endpoint means strongly depend on the forcing and thus time. The spread in the historical experiment cannot be expected to be as small as in the idealized experiments, because a large diversity in aerosol load and distribution (e.g., Stevens 2015) causes a variable forcing on the respective model's atmospheric heat budget. Aerosols have been shown to exert a great impact on the intermodel spread of $\eta_{a}$ in the CMIP3 ensemble (e.g., Previdi 2010; Pendergrass and Hartmann 2012). In addition, the natural variability is high compared to the signal from the forcing, which increases the intermodel spread of the estimated slope. The effect of natural variability is also apparent in Hegerl et al. (2015), where the spread in the representative concentration pathways (RCPs) reduces with increasing forcing (see their Fig. 1b).

The merit of estimating $\eta_{a}$ for a transient experiment with such variable forcings on the atmospheric heat budget remains questionable because physical reasons for intermodel spread in $\eta_{a}$ are difficult to disentangle. On the contrary, the concept of $\eta$ reveals that models in fact agree well on the magnitude of $\eta$.

We consider the estimate in $\eta$ from abrupt $4 \mathrm{xCO} 2$ as the most appropriate estimate for the CMIP5 model 
TABLE 2. Values of $\eta$ and $\eta_{a}$ from different CMIP5 experiments $\left(\mathrm{W} \mathrm{m}^{-2} \mathrm{~K}^{-1}\right.$, values in parentheses have the unit \% $\left.\mathrm{K}^{-1}\right)$. Error estimates are given as plus or minus one standard error from the ordinary least squares regression. Ensemble error is plus or minus one ensemble standard deviation. The models are ordered such that their $\eta$ value in the abrupt $4 \mathrm{xCO} 2$ simulation increases. Data have been horizontally interpolated to a common T63 spectral truncation Gaussian grid prior to analysis. (Expansions of acronyms are available online at http://www.ametsoc.org/PubsAcronymList.)

\begin{tabular}{|c|c|c|c|c|c|}
\hline Model & historical $\left(\eta_{a}\right)$ & $1 \operatorname{pctCO} 2\left(\eta_{a}\right)$ & abrupt4xCO2 $(\eta)$ & $\operatorname{amip} 4 \mathrm{~K}(\eta)$ & Reference \\
\hline ACCESS1.0 & $0.47 \pm 0.15$ & $0.82 \pm 0.01$ & $1.85 \pm 0.02(2.06 \pm 0.02)$ & - & Bi et al. (2013) \\
\hline BNU-ESM & $0.93 \pm 0.07$ & $1.22 \pm 0.02$ & $1.87 \pm 0.03(2.14 \pm 0.04)$ & - & Ji et al. (2014) \\
\hline HadGEM2-A & - & - & - & 2.32 & Collins et al. (2011) \\
\hline HadGEM2-ES & $0.70 \pm 0.20$ & $0.98 \pm 0.01$ & $1.90 \pm 0.02(2.13 \pm 0.02)$ & - & Collins et al. (2011) \\
\hline FGOALS-s2 & - & $1.45 \pm 0.02$ & $1.92 \pm 0.04(2.49 \pm 0.05)$ & - & Bao et al. (2013) \\
\hline CanESM2 & $0.84 \pm 0.07$ & $1.10 \pm 0.02$ & $1.97 \pm 0.03(2.48 \pm 0.03)$ & - & Arora et al. (2011) \\
\hline CanAM4 & - & - & - & 2.55 & von Salzen et al. (2013) \\
\hline FGOALS-g2 & $1.44 \pm 0.09$ & $1.29 \pm 0.01$ & $1.99 \pm 0.02(2.44 \pm 0.02)$ & 2.59 & Li et al. (2013) \\
\hline GFDL-ESM2G & $1.26 \pm 0.10$ & $0.82 \pm 0.05$ & $2.01 \pm 0.03(2.34 \pm 0.04)$ & - & Dunne et al. (2012) \\
\hline MIROC-ESM & $0.08 \pm 0.09$ & $1.37 \pm 0.01$ & $2.08 \pm 0.03(2.56 \pm 0.03)$ & - & Watanabe et al. (2011) \\
\hline MPI-ESM-LR & $1.19 \pm 0.07$ & $1.42 \pm 0.01$ & $2.15 \pm 0.03(2.54 \pm 0.04)$ & 2.74 & Stevens et al. (2013) \\
\hline GFDL-ESM2M & $1.50 \pm 0.12$ & $1.12 \pm 0.04$ & $2.17 \pm 0.03(2.53 \pm 0.04)$ & - & Dunne et al. (2012) \\
\hline BCC_CSM1.1 & $1.26 \pm 0.04$ & $1.33 \pm 0.01$ & $2.18 \pm 0.03(2.69 \pm 0.04)$ & 2.74 & Wu et al. (2014) \\
\hline MPI-ESM-MR & $1.29 \pm 0.09$ & $1.53 \pm 0.02$ & $2.23 \pm 0.04(2.59 \pm 0.04)$ & 2.93 & Giorgetta et al. (2013) \\
\hline ACCESS1.3 & $0.76 \pm 0.16$ & $1.46 \pm 0.02$ & $2.24 \pm 0.03(2.44 \pm 0.03)$ & - & Bi et al. (2013) \\
\hline CNRM-CM5 & $0.42 \pm 0.17$ & $1.27 \pm 0.02$ & $2.24 \pm 0.03(2.52 \pm 0.03)$ & 2.77 & Voldoire et al. (2013) \\
\hline IPSL-CM5B-LR & $1.51 \pm 0.06$ & $1.06 \pm 0.02$ & $2.24 \pm 0.04(2.79 \pm 0.05)$ & 2.89 & Hourdin et al. (2013) \\
\hline CSIRO Mk3.6.0 & $0.29 \pm 0.14$ & $1.47 \pm 0.02$ & $2.25 \pm 0.02(2.68 \pm 0.03)$ & - & Rotstayn et al. (2012) \\
\hline MPI-ESM-P & $1.03 \pm 0.07$ & $1.42 \pm 0.01$ & $2.25 \pm 0.03(2.66 \pm 0.04)$ & - & Giorgetta et al. (2013) \\
\hline GFDL CM3 & $0.82 \pm 0.20$ & $1.37 \pm 0.02$ & $2.26 \pm 0.03(2.56 \pm 0.03)$ & - & Donner et al. (2011) \\
\hline NorESM1-M & $0.84 \pm 0.12$ & $1.05 \pm 0.02$ & $2.32 \pm 0.03(2.86 \pm 0.04)$ & - & Bentsen et al. (2013) \\
\hline CCSM4 & $1.43 \pm 0.06$ & $1.22 \pm 0.01$ & $2.39 \pm 0.03(2.82 \pm 0.04)$ & 3.10 & Meehl et al. (2012) \\
\hline BCC_CSM1.1(m) & $1.55 \pm 0.05$ & $1.58 \pm 0.02$ & $2.40 \pm 0.03(2.97 \pm 0.04)$ & - & Wu et al. (2014) \\
\hline MIROC5 & $0.72 \pm 0.12$ & $1.15 \pm 0.02$ & $2.42 \pm 0.06(2.61 \pm 0.06)$ & 2.71 & Watanabe et al. (2010) \\
\hline INM-CM4.0 & $1.38 \pm 0.08$ & $1.26 \pm 0.02$ & $2.43 \pm 0.06(2.69 \pm 0.06)$ & - & Volodin et al. (2010) \\
\hline GISS-E2-H & $0.74 \pm 0.08$ & $1.36 \pm 0.01$ & $2.49 \pm 0.03(2.68 \pm 0.03)$ & - & Schmidt et al. (2014) \\
\hline IPSL-CM5A-LR & $1.60 \pm 0.05$ & $1.50 \pm 0.01$ & $2.51 \pm 0.02(3.27 \pm 0.03)$ & 2.83 & Dufresne et al. (2013) \\
\hline IPSL-CM5A-MR & $1.81 \pm 0.07$ & $1.49 \pm 0.01$ & $2.57 \pm 0.03(3.24 \pm 0.03)$ & - & Dufresne et al. (2013) \\
\hline GISS-E2-R & $0.38 \pm 0.14$ & $1.27 \pm 0.02$ & $2.63 \pm 0.05(2.86 \pm 0.06)$ & - & Schmidt et al. (2014) \\
\hline MRI-CGCM3 & $-0.19 \pm 0.22$ & $1.92 \pm 0.02$ & $2.73 \pm 0.05(3.22 \pm 0.06)$ & 3.30 & Yukimoto et al. (2012) \\
\hline Ensemble & $0.97 \pm 0.51$ & $1.30 \pm 0.24$ & $2.24 \pm 0.24(2.64 \pm 0.30)$ & $2.79 \pm 0.26$ & - \\
\hline
\end{tabular}

ensemble for the rate of increase in precipitation with surface warming. The estimate, with absolute model spread of $1.85-2.73 \mathrm{~W} \mathrm{~m}^{-2} \mathrm{~K}^{-1}$ (with a factor of 1.5 between the highest and lowest model estimate) and a dispersion of $10.7 \%$, supports the results in Andrews et al. (2009), who also find a factor of 1.5 spread among models. Why is the intermodel spread in $\eta$ larger in the remaining studies (Table 1 )?

The analysis above demonstrates that the spread in the slope of precipitation increase is larger when $\eta_{a}$ is calculated (Held and Soden 2006; Previdi 2010; Pendergrass and Hartmann 2014). Studies that estimate $\eta$ from transient multiexperiment model ensembles via a multiple regression analysis must make assumptions for the magnitude of forcings, finding larger spreads (Lambert and Allen 2009; Frieler et al. 2011). Takahashi (2009) finds the best estimate from a multimodel multirun ensemble by looking at two transient and one steplike $\mathrm{CO}_{2}$ and accounting for adjustments. The larger dispersion $(19 \%)$ in that study may arise from a different application of the regression method. Lambert and Webb (2008) calculate $\eta$ from the 2xCO2 CMIP3 experiment and from a large ensemble of models with physically perturbed atmospheric subgrid-scale parameters. Probably the analysis of models with physically perturbed parameters initiated the larger spread in

TABLE 3. Comparison of the regression and the endpoint method. The regression method applied to abrupt $4 \mathrm{xCO} 2$ yields $\eta$; all other estimates yield $\eta_{a}$. Values shown are the ensemble mean plus or minus one ensemble standard deviation, and in parentheses are the minimum-maximum range of model values $\left(\mathrm{W} \mathrm{m}^{-2} \mathrm{~K}^{-1}\right)$.

\begin{tabular}{lcc}
\hline \multicolumn{1}{c}{ Experiment } & \multicolumn{1}{c}{ Regression } & Endpoint \\
\hline historical & $0.97 \pm 0.51(-0.19-1.81)$ & $0.44 \pm 0.94(-1.64-1.76)^{\mathrm{a}}$ \\
1 pctCO2 & $1.30 \pm 0.24(0.82-1.92)$ & $1.28 \pm 0.23(0.72-1.88)$ \\
abrupt4xCO2 & $2.24 \pm 0.24(1.85-2.73)$ & $1.39 \pm 0.25(0.91-1.97)$ \\
\hline
\end{tabular}

${ }^{a}$ Endpoint ensemble estimates for the historical experiment exclude GFDL CM3 for which $\eta_{a}=-16.4 \mathrm{~W} \mathrm{~m}^{-2} \mathrm{~K}^{-1}$. 
Lambert and Webb (2008) (factor of 2.4 difference), but such experiments are less constrained estimates of the present climate. The large number of CMIP5 models analyzed here may therefore be considered as a representative sample to infer that intermodel differences result in a factor of 1.5 spread in $\eta$ among models, which is comparably small to what has been estimated in most previous work.

\section{Applicability of the hydrological sensitivity parameter to transient experiments}

We have shown that the hydrological sensitivity parameter is a robust measure in the idealized abrupt $4 \mathrm{xCO} 2$ experiment, but $\eta_{a}$ found in transient forcing simulations is sensitive to the experimental configuration. Transient forcings, however, are more realistic, as an abrupt quadrupling of $\mathrm{CO}_{2}$ concentration is not expected to happen in reality.

Of what use is then a measure estimated from the abrupt $4 \mathrm{xCO} 2$ simulations to understand precipitation change in the more complex reality? Thorpe and Andrews (2014) demonstrated that $\eta$ estimated from abrupt $4 \mathrm{xCO} 2$ serves well for predicting the overall precipitation response in the historical and different RCP experiments, simply by considering fast precipitation adjustments to aerosols, ozone, $\mathrm{CO}_{2}$, solar changes, and other greenhouse gases. For this analysis, TOA forcing estimates for the different forcing agents had to be converted into atmospheric forcings, but the conversion ratios were known for only two models and thus had to be applied to the rest of the models. Consequently, the total spread of $\Delta P$ could not be exactly predicted.

Here we ask how well precipitation changes in the transient $1 \mathrm{pctCO} 2$ can be predicted by only knowing the temperature-dependent precipitation response $\eta$ and the fast precipitation adjustment $A$ from abrupt $4 \mathrm{xCO} 2$. To do so, we scale $A$ (the adjustment for a $4 \times \mathrm{CO}_{2}$ increase) by the relative change in forcing in year $n$ to predict $\Delta P$ :

$$
\Delta P_{\text {pred }, n}=\eta \Delta T_{s, n}+A \frac{n}{2} \log _{2} 1.01 .
$$

The scaling factor multiplying $A$ has been estimated by assuming that the forcing increases linearly with the logarithm of the $\mathrm{CO}_{2}$ concentration, which increases at $1 \% \mathrm{yr}^{-1}$. It is thus identically one at the time of $\mathrm{CO}_{2}$ quadrupling (i.e., $n=139.32 \mathrm{yr}$ ). This approach is similar to the one adopted by Good et al. (2012).

The predicted evolution of precipitation changes with surface temperature changes coincides with the overall model precipitation change (Fig. 3a). Apart from the two GISS models, the absolute difference between predicted and model $\Delta P$ is smaller than approximately $\pm 0.9 \mathrm{~W} \mathrm{~m}^{-2}$
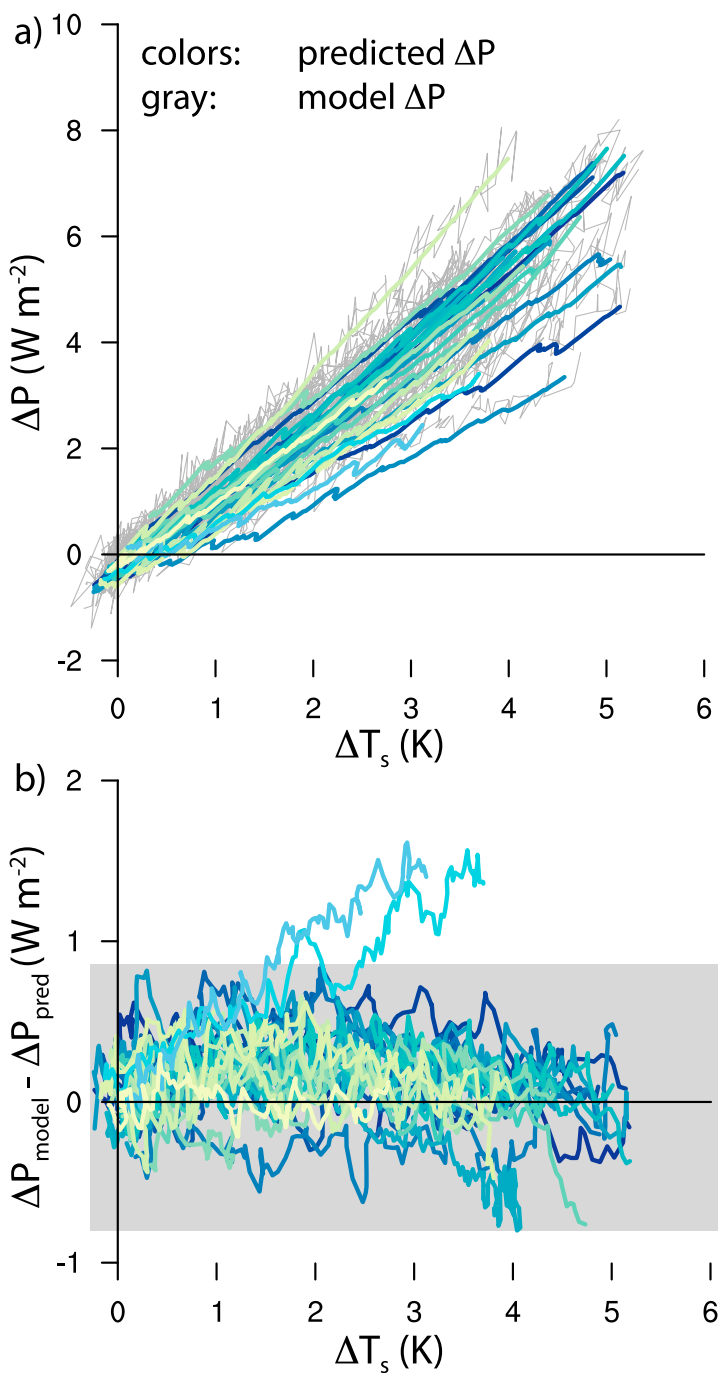

FIG. 3. (a) Evolution of annual-mean $\Delta P$ with corresponding $\Delta T_{s}$ in the $1 \mathrm{pctCO} 2$ experiment, with respect to the climatological mean in piControl. Gray thin lines show actual model results, and colored thick lines the predicted precipitation change following Eq. (2). (b) Absolute deviation of predicted and model $\Delta P$. All colored lines are smoothed by a 5 -yr running average. The gray shading ranges from -0.80 to $0.86 \mathrm{~W} \mathrm{~m}^{-2}$. All 1 pctCO2 experiments from Table 2 are shown, except GFDL-ESM2M and GFDL-ESM2G as our analysis suggests that their $\mathrm{CO}_{2}$ increase stopped after 70 years.

(or $\pm 0.03 \mathrm{~mm} \mathrm{day}^{-1}$ ) as shown by the gray shading (Fig. 3b). Precipitation increases nonlinearly with surface warming in the GISS models in the abrupt $4 \mathrm{xCO} 2$ experiment, which leads to ambiguity in the estimates of $\eta$ and $A$, resulting in a biased $\Delta P_{\mathrm{pred}, n}$. The good agreement in the other models, however, suggests that idealized climate change experiments may serve well in projecting the global-mean precipitation response.

From this we deduce that the difficulties to exactly project $\Delta P$ in Thorpe and Andrews (2014) arose from 
uncertainties in forcing estimates other than from $\mathrm{CO}_{2}$. For here it is shown that $\eta$ and $A$, estimated from abrupt $4 \mathrm{xCO} 2$ experiments, can predict the precipitation change in a transient $\mathrm{CO}_{2}$ experiment reasonably well.

\section{Sources of intermodel spread in the global-mean precipitation response on different time scales}

In this section we address the causes of intermodel spread in the precipitation response on different time scales whereas the previous sections investigated the degree of difference among models in the slope of precipitation change with surface temperature change. As we have shown that the intermodel spread in the slope $(\eta)$ corresponds to the smallest estimate of spread in the literature, one might think that global-mean precipitation predictions from models would converge toward the same value. Nevertheless, the global-mean equilibrium precipitation response to an abrupt $4 \times \mathrm{CO}_{2}$ forcing - hereafter $\mathrm{EHS}_{4 \times}$ - exhibits a factor of 3 spread among CMIP5 models, even though $\eta$ has a twofold smaller factor of spread (1.5) in the same experiment (section 3).

Which factors, then, determine the larger spread in $\mathrm{EHS}_{4 \times}$ ? Assuming that $\Delta P$ linearly increases with $\Delta T_{s}$, the spread in $\mathrm{EHS}_{4 \times}$ is affected by the spread in equilibrium climate sensitivity for a quadrupling of $\mathrm{CO}_{2}$ $\left(\mathrm{ECS}_{4 \times}\right)$, the hydrological sensitivity parameter, and the adjustment (Fig. 4a).

At equilibrium, it is the spread in $\mathrm{ECS}_{4 \times}$ that primarily impacts the large range of $\mathrm{EHS}_{4 \times}$ (Fig. 4b). Here the respective standard deviations $\sigma_{i}$, with $i$ being $A, \eta$, or $\mathrm{ECS}_{4 \times}$, are normalized by the standard deviation of $\mathrm{EHS}_{4 \times}$, yielding $\widehat{\sigma}_{i}$. When comparing the respective contributions to $\sum_{i} \widehat{\sigma}_{i}$, then $\mathrm{ECS}_{4 \times}$ on its own makes up $57 \%$ of the spread, whereas $A$ and $\eta$ contribute with only $16 \%$ and $27 \%$, respectively. Thus, $\mathrm{ECS}_{4 \times}$ conditions the spread of the $\mathrm{EHS}_{4 \times}$. In fact, if only the spread in $\mathrm{ECS}_{4 \times}$ were to determine the spread in $\mathrm{EHS}_{4 \times}$, the spread in $\mathrm{EHS}_{4 \times}$ would be slightly larger $\left(\hat{\sigma}_{\mathrm{ECS}_{4 \times}}=1.07\right)$. An anticorrelation between $\eta$ and $\mathrm{ECS}_{4 \times}$ leads to smaller $\Delta P$ for models with high surface temperature warming and vice versa; the spread of $\mathrm{EHS}_{4 \times}$ is thus smaller when $\eta$ and $A$ can vary than if only $\mathrm{ECS}_{4 \times}$ caused the spread. Our conclusion, that the spread in $\mathrm{ECS}_{4 \times}$ dominates the spread in $\mathrm{EHS}_{4 \times}$ is consistent with other analysis (Thorpe and Andrews 2014).

The spread in adjustment is important in the early stages of warming, where the spread in adjustment dominates over the influence of differing surface warming among models, with about $45 \%$ contribution to the sum of $\widehat{\sigma}_{i}$ (Fig. 5). The importance of $\eta$ rises with

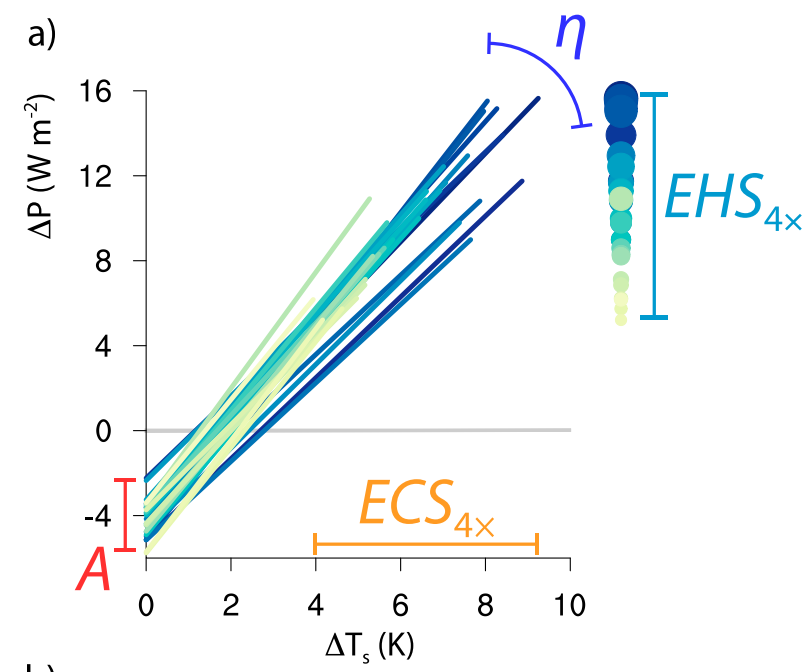

b)

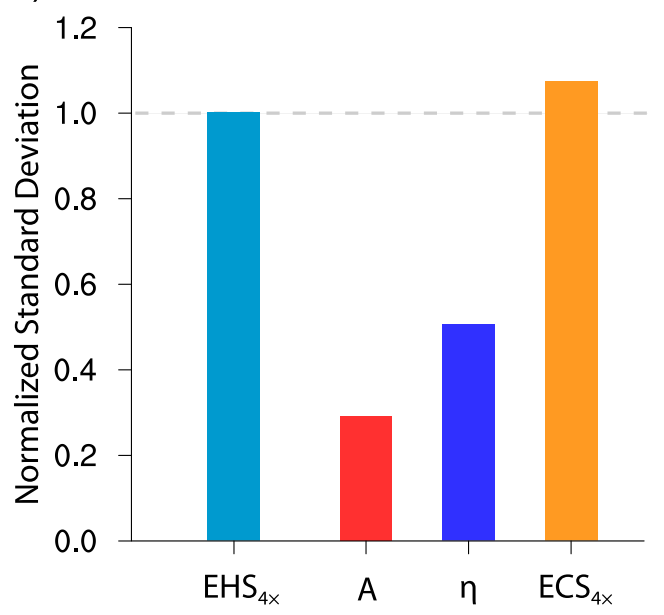

FIG. 4. (a) Shown are $A, \eta$, and $\mathrm{ECS}_{4 \times}$ in the 28 abrupt $4 \mathrm{xCO} 2$ models. Dots denote $\mathrm{EHS}_{4 \times}$, where dot size increases for larger $\mathrm{EHS}_{4 \times}$. Colors darken for increasing $\mathrm{ECS}_{4 \times}$. (b) Contributions to spread in $\mathrm{EHS}_{4 \times}$ from $A, \eta$, and $\mathrm{ECS}_{4 \times}$; estimated via Eq. (1), by setting two of the three factors to their corresponding ensemblemean values. The standard deviations of $\Delta P$ due to variation of the free factors are normalized by the actual standard deviation in equilibrium $\Delta P$. Note that normalized standard deviations do not add to unity.

warming, surpassing the adjustment's contribution to $\sum_{i} \widehat{\sigma}_{i}$ after about 20 years. The residual, given as offset between model $\Delta P$ and that of the regression line following Eq. (1), amounts to about $20 \%$ in the very beginning but reduces with time. The residual is due both to errors in the prediction and to internal variability. Uncertainty due to surface warming only overwhelms the combined effect of $\hat{\sigma}_{\eta}+\hat{\sigma}_{A}$ after year 70 of the abrupt $4 \mathrm{xCO} 2$ simulation (Fig. 5).

To understand the spread in precipitation response over all time scales, it is thus necessary to better understand separate sources of spread for equilibrium 


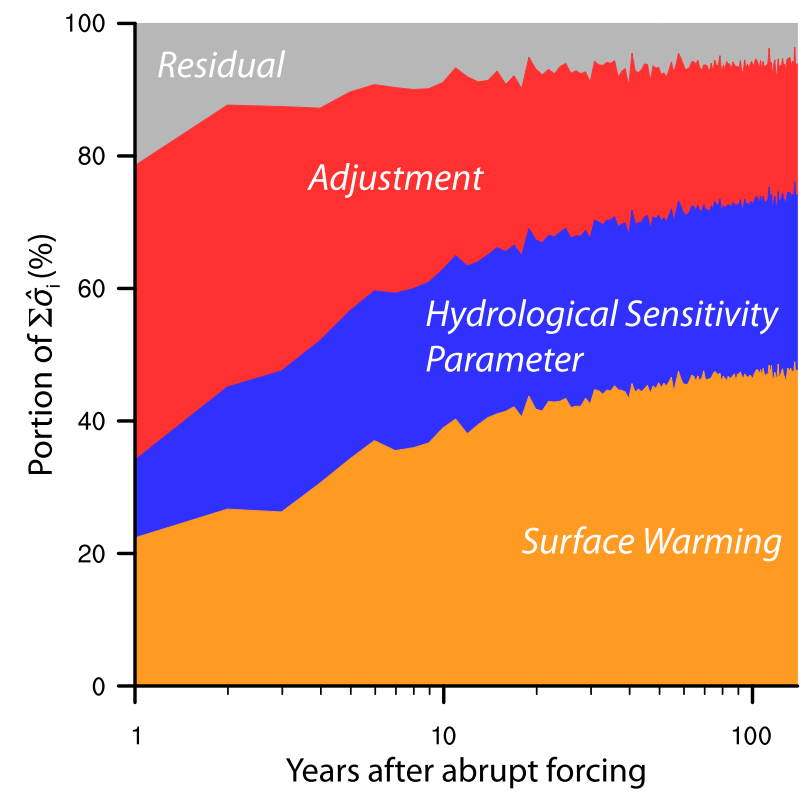

FIG. 5. Contributions of surface warming, hydrological sensitivity parameter, adjustment, and residual to the sum of their respective normalized standard deviation $\widehat{\sigma}_{i}$ as a function of years after the $4 \times \mathrm{CO}_{2}$ forcing. Note the logarithmic time scale. The $\widehat{\sigma}_{i}$ values are estimated as in Fig. $4 \mathrm{~b}$ but for annual-mean standard deviations of $\Delta P$. The residual contribution is given by the portion of normalized standard deviation of differences between model and calculated $\Delta P$ following Eq. (1).

surface warming, $\eta$ and $A$. All three spread-causing factors are determined by how the energy fluxes of the system change in response to the $\mathrm{CO}_{2}$ forcing in the abrupt $4 \mathrm{xCO} 2$ models. The analysis of spread-causing factors in the energetics of the atmosphere thus serves as a straightforward approach for better understanding the variation in precipitation response.

Since the 1970s when general circulation models were first established, extensive effort has been placed on developing a framework for understanding contributions to the spread in ECS (Charney et al. 1979). This framework has made it possible to decompose the temperature response into radiative contributions from climate change feedbacks: temperature, cloud, water vapor, and surface albedo feedback. The uncertainty in ECS estimates originates foremost from the uncertainty in simulated cloud feedback (e.g., Cess et al. 1990; Dufresne and Bony 2008), and in particular in the shortwave component of the low-cloud feedback (e.g., Bony and Dufresne 2005; Zelinka et al. 2012; Vial et al. 2013). The path toward better constraining the spread in climate sensitivity has thus been comprehensively laid out.

Less attention has been focused on understanding intermodel spread in the slope of precipitation change with surface temperature change and in the rapid adjustment. Previdi (2010), one of the pioneers in this undertaking, diagnosed the radiative impact of changing atmospheric variables on the atmospheric heat budget. In so doing, the respective contributions of these radiative effects could be attributed to $\eta_{a}$. That study, however, was based on an experiment which was simultaneously forced by $\mathrm{CO}_{2}$ and aerosols, where the latter has subsequently been found to dominate the intermodel spread in $\eta_{a}$ (Pendergrass and Hartmann 2012). O'Gorman et al. (2012), extending the analysis of Previdi (2010) for the same experiment, emphasized that different changes of clouds in the models cause larger intermodel scatter than lapse rate plus water vapor changes. Using a different methodology, Pendergrass and Hartmann (2014) found that both clear-sky radiative cooling spread, resulting from differing changes in lapse rate plus moistening, and cloudy-sky radiative cooling spread contribute to intermodel scatter in $\eta_{a}$.

None of the above studies, however, addressed intermodel spread in $\eta$ and $A$ due to radiative effects from changing atmospheric variables, for instance by separating between the fast and temperature-dependent atmospheric heat budget changes resulting from abruptly increased $\mathrm{CO}_{2}$ levels. This knowledge would seem helpful for gaining insight into the sources of spread in precipitation response resulting from the spread in the adjustment and the hydrological sensitivity parameter, especially for early years of warming (Fig. 5). To this end, we perform radiative decompositions of the spread in $\eta$ and $A$ in the abrupt $4 \times \mathrm{xCO} 2$ experiment.

\section{a. Radiative decomposition of the spread in $\eta$ and $A$}

We decompose the changes of the atmospheric radiative imbalance $\left(\Delta R=\Delta R^{\mathrm{TOA}}-\Delta R^{\text {surface }}\right)$ in the abrupt $4 \mathrm{xCO} 2$ by the kernel method (Soden et al. 2008). The decomposition is performed such that

$$
L_{v} \Delta P \approx \sum \Delta R_{x}-\Delta \mathrm{SH},
$$

where SH is the sensible heat flux and the latent heat of vaporization $L_{v}=2500 \mathrm{~kJ} \mathrm{~kg}^{-1}$; the index $x$ denotes contributions from $\mathrm{CO}_{2}$ plus stratospheric temperature changes $\left(\mathrm{CO}_{2}+\right.$ Strat $)$, changes in the tropospheric temperature lapse rate (LR), changes due to uniform tropospheric warming arising from surface temperature increase (Planck), changes in water vapor (WV), changes in surface albedo, and changes in clouds. The investigation of the decomposed slope from the regression of $\Delta R_{x}$ against $\Delta T_{s}$ provides information for sources of spread in the hydrological sensitivity parameter $\eta_{x}$ and the $y$ intercept of the regression for sources of spread in the rapid precipitation adjustment $A_{x}$. 
To isolate $\Delta R_{x}$ from changes in the atmospheric heat budget for individual changes in atmospheric state variables $\Delta x$, we follow the technique described by Previdi (2010), but employ a newer kernel (Block and Mauritsen 2013) calculated with the MPI-ESM-LR model (Stevens et al. 2013), which is then used for every model in this analysis. The kernels are vertically interpolated to the CMIP5 pressure levels and mass-weighted by the pressure thickness of each vertical layer. Any $\Delta x$ is derived as a monthly mean deviation in abrupt $4 \mathrm{xCO} 2$ from the climatological mean of all available piControl months in the given model, preserving the monthly, regional, and vertical structure. Afterward $\Delta x$ is interpolated to the same horizontal resolution as the applied kernel (the Gaussian grid of T63 spectral truncation) before performing the radiative decomposition. We choose to interpolate the model variables to the kernel grid because the temperature and water vapor kernels have sharp gradients in orographic areas, where grid points below the surface are defined as missing values. Interpolation of fields with stronger gradients introduces more errors. Detailed information about the MPI-ESM-LR kernels is given in Block and Mauritsen (2013).

We illustrate the practicalities of our calculations by the example of the lapse-rate component of the hydrological sensitivity parameter [see Previdi (2010) for more details on the kernel method applied to the atmospheric heat budget]. The lapse rate change $\Delta \mathrm{LR}$ is defined as the change in deviation of tropospheric temperature from a uniform tropospheric warming equal to the change in surface temperature. The change in atmospheric radiative fluxes due to a lapse rate change $\Delta R_{\mathrm{LR}}$ is then given by the vertical integral from the surface to the tropopause $\Delta R_{\mathrm{LR}} \approx \int_{p_{s}}^{p_{t}} k_{T} \Delta \mathrm{LR} d p$, where $p$ denotes pressure and the subscripts $s$ and $t$ surface and tropopause. The temperature kernel $k_{T}$ is the change of atmospheric radiative fluxes due to a unit temperature change at a given grid point and vertical level. Deducing from $k_{T}$ (see Fig. S1 of the supplementary material), a temperature increase by $1 \mathrm{~K}$ leads to increases of atmospheric cooling at any vertical level, but this effect is stronger in the lower troposphere. Similarly to Soden et al. (2008), the tropopause is approximated to be at $100 \mathrm{hPa}$ in the tropics $\left(30^{\circ} \mathrm{N}-30^{\circ} \mathrm{S}\right)$ and linearly drops in height with increasing latitude toward $300 \mathrm{hPa}$ at the poles. The stratospheric temperature changes are considered in the $x=\mathrm{CO}_{2}+$ Strat term, where the contributions are first calculated separately using a $\mathrm{CO}_{2}$ kernel and by multiplying stratospheric temperature changes with the temperature kernel before summing both terms.

Then $\eta_{\mathrm{LR}}$ arises from the slope found by ordinaryleast squares regression of annual global-mean $\Delta R_{\mathrm{LR}}$ versus $\Delta T_{s}$; the $y$ intercept gives $A_{\mathrm{LR}}$. Almost all abrupt $4 \mathrm{xCO} 2$ models from Table 2 are included in the following results, except FGOALS-g2 and CSIRO Mk3.6.0 as they did not provide all necessary variables for this analysis. Signs are chosen in terms of atmospheric heating; negative contributions lead to stronger cooling, which is balanced by increases in $\eta$ or a less strong adjustment. The other $\eta_{x}$ and $A_{x}$ are estimated with the standard kernel technique, but for atmospheric radiative convergence instead of TOA radiative fluxes.

\section{b. Spread in the hydrological sensitivity parameter}

Intermodel spread of atmospheric heating changes with warming in the abrupt $4 \mathrm{xCO} 2$ experiment is dominated by large absolute and interquartile ranges of lapse rate and cloud-induced radiative changes with warming (Fig. 6a), whereas models agree well on the magnitude of radiative contributions coming from surface albedo changes, Planck effect, and water vapor and sensible heat flux changes.

To better assess the spread due to changes in the thermodynamic structure of the troposphere, contributions to $\Delta P$ from lapse rate and water vapor changes are considered together $\left(\eta_{\mathrm{LR}+\mathrm{WV}}\right)$, as the water vapor concentration increases with temperature approximately following the Clausius-Clapeyron equation (e.g., Trenberth et al. 2005; Held and Soden 2006). The separation of $\eta_{\mathrm{LR}+\mathrm{WV}}$ into three vertical layers reveals that models disagree most in the lower tropospheric changes (Fig. 6b). Although intermodel spreads of $\eta_{\mathrm{LR}}$ and $\eta_{\mathrm{WV}}$ in the middle and upper troposphere are individually as large as or even larger than in the lower troposphere (not shown), they cancel almost perfectly in the middle and upper troposphere because $\eta_{\mathrm{LR}}$ and $\eta_{\mathrm{WV}}$ are anticorrelated (with $r=-0.89$ and $r=-0.92$ ). In the lower troposphere, however, $\eta_{\mathrm{LR}}$ and $\eta_{\mathrm{WV}}$ correlate positively $(r=0.61)$. The opposite correlation between the lower and upper troposphere can be understood by considering how increases in water vapor and temperature modify the radiative budget at the surface and TOA (Pendergrass and Hartmann 2014). In the upper troposphere, increases of water vapor lead to less radiative cooling at the TOA, while increased surface temperatures lead to more cooling; the uncertainties cancel approximately. Increased water vapor and temperature in the lower troposphere both lead to more cooling of the atmosphere to the surface; hence uncertainties due to the models' lower tropospheric temperature and humidity structure amplify the lower tropospheric spread in $\eta_{\mathrm{LR}+\mathrm{wV}}$. Further separation of the lower tropospheric changes into three regions - the tropics, midlatitudes, and poles-indicates that the spread in the lower troposphere mainly emerges 
a) $\left(\mathrm{W} \mathrm{m}^{-2} \mathrm{~K}^{-1}\right)$

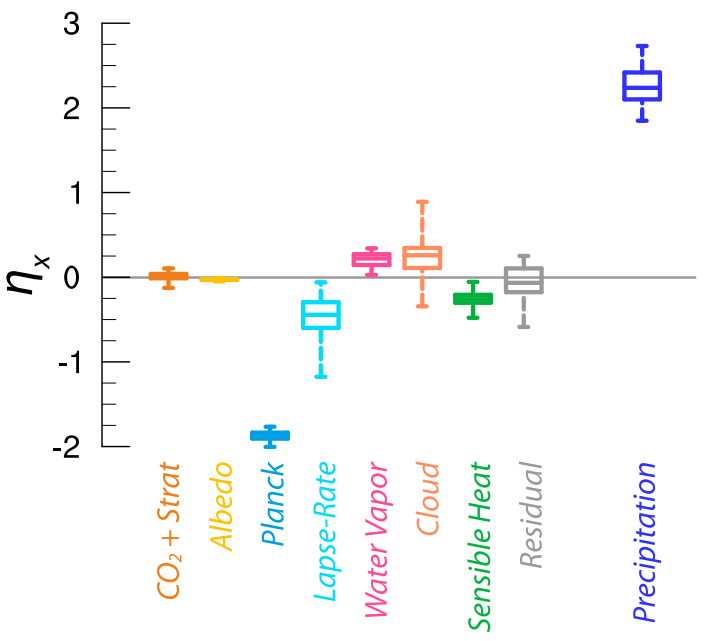

b) $\left(\mathrm{W} \mathrm{m}\right.$ m $\left.^{-2} \mathrm{~K}^{-1}\right)$

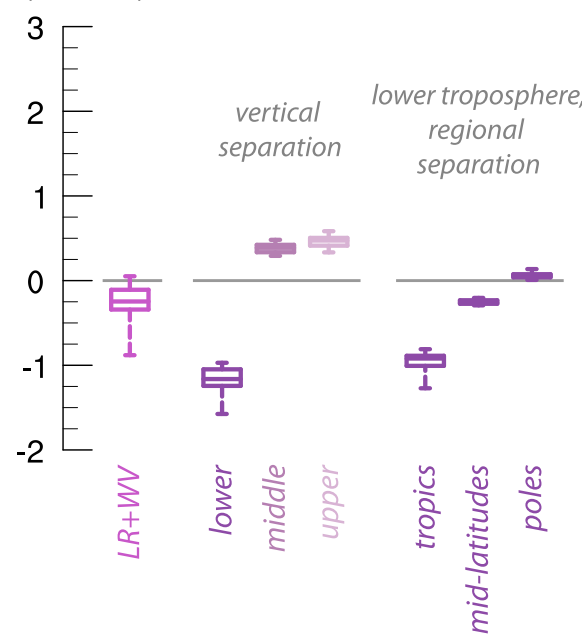

FIG. 6. (a) Decomposition of $\eta$ for 26 abrupt4xCO2 models. Box-and-whisker plots show the minimum and maximum as the whiskers; the box shows the first quartile, the median, and the third quartile as horizontal lines. The residual is the difference between model $\Delta R / \Delta T_{s}$ and $\sum_{x} \eta_{x}$. (b) Vertical separation of $\eta_{\mathrm{LR}+\mathrm{WV}}$ into the lower $(p>$ $700 \mathrm{hPa})$, middle $(700 \geq p>400 \mathrm{hPa})$, and upper $(400 \geq p \geq 100 \mathrm{hPa})$ troposphere. The lower tropospheric $\eta_{\mathrm{LR}+\mathrm{WV}}$ is further separated into regions and shown here for the tropics (equatorward of $\pm 30^{\circ}$ ), the midlatitudes (from $\pm 30^{\circ}$ to $\pm 60^{\circ}$ ), and the poles (poleward of $\pm 60^{\circ}$ ). For any separation, first $\Delta R_{x}$ is vertically integrated at each grid point and month, then if applicable, regionally averaged and last regressed against global annual-mean $\Delta T_{s}$.

from differing model responses of the lower tropospheric structure in tropical areas (Fig. 6b).

That intermodel spread does not reduce strongly by summing up lapse rate and water vapor changes may appear surprising as these are usually thought to offset each other to a large degree (e.g., Bony et al. 2006). This thought, however, arises from considering how lapse rate and water vapor changes affect the TOA fluxes and not the surface. For the spread of $\eta_{\mathrm{LR}+\mathrm{WV}}$ and $\eta_{\mathrm{LR}}$ to be commensurate (Fig. 6), this implies that the spread originates in the surface contribution to the atmospheric heating. Our results agree well with Pendergrass and Hartmann (2014), who also conclude that the radiative effects of lapse rate and water vapor changes do not compensate each other in the atmosphere. These results differ, however, from the findings of O'Gorman et al. (2012), who report a smaller intermodel spread in $\eta_{\mathrm{LR}+\mathrm{WV}}$ than in the respective $\eta_{\mathrm{LR}}$ or $\eta_{\mathrm{WV}}$.

In terms of precipitation magnitude, warming of the troposphere (with medians of $\eta_{\text {Planck }}=-1.86 \mathrm{~W} \mathrm{~m}^{-2} \mathrm{~K}^{-1}$ and $\left.\eta_{\mathrm{LR}}=-0.44 \mathrm{~W} \mathrm{~m}^{-2} \mathrm{~K}^{-1}\right)$ is the single most important determinant for the increase in precipitation with surface warming $\left(\eta=2.24 \mathrm{~W} \mathrm{~m}^{-2} \mathrm{~K}^{-1}\right)$ by increasing the longwave atmospheric cooling on a global mean basis (Fig. 6a). A less important source of precipitation increase is the sensible heat flux $\left(\eta_{\mathrm{SH}}=-0.26 \mathrm{~W} \mathrm{~m}^{-2} \mathrm{~K}^{-1}\right)$; the magnitude of the sensible heat flux decreases with warming in all models, which must be offset by more precipitation. The precipitation increase is dampened by changes in water vapor $\left(\eta_{\mathrm{WV}}=0.22 \mathrm{~W} \mathrm{~m}^{-2} \mathrm{~K}^{-1}\right)$ and clouds $\left(\eta_{\text {Cloud }}=\right.$ $0.26 \mathrm{~W} \mathrm{~m}^{-2} \mathrm{~K}^{-1}$ ) in most models. Although increases of water vapor concentration enhance the longwave cooling of the atmosphere $\left(\eta_{\mathrm{WV}, \mathrm{LW}}=-0.66 \mathrm{~W} \mathrm{~m}^{-2} \mathrm{~K}^{-1}\right)$, this cooling is overcompensated by the additional absorption of shortwave radiation by the water vapor $\left(\eta_{\mathrm{Wv}, \mathrm{sw}}=0.87 \mathrm{~W} \mathrm{~m}^{-2} \mathrm{~K}^{-1}\right)$. Contrary to our study, Previdi (2010) and O'Gorman et al. (2012) find that $\eta_{\mathrm{WV}, \mathrm{LW}}>0$, although both studies use a very similar methodology to ours. Qualitative comparison suggests that probably the opposing results are caused by differences in the longwave water vapor kernel (see the discussion around Fig. S1 in the supplementary material), particularly in the lower troposphere. However, our calculations concerning $\eta_{\mathrm{WV}, \mathrm{LW}}$ are in line with the findings of other studies (Mitchell et al. 1987; Pendergrass and Hartmann 2014).

Noteworthy challenges remain in better separating contributions of radiative effects on $\eta$ with the kernel method, as there exists a considerable spread in the residual between $\sum_{x} \Delta R_{x}$ and the model atmospheric heat budget change (Fig. 6a). Because only one set of kernels derived from a single model in a preindustrial state was employed to perform the decomposition in the individual models, a residual may reflect differences in host model treatments of radiative transfer particularly in the shortwave spectrum (Takahashi 2009; Pendergrass and Hartmann 2014). Although more shortcomings of the kernel method exist, a better method that addresses 
these issues and is as computationally and practically feasible has yet to be developed.

Presenting the residual of the kernel decomposition is important for validating the kernel calculations and to gain confidence in the results. We test whether the scatter of the residual arises from systematic offsets in any of the $\eta_{x}$. No single $\eta_{x}$ is responsible for the residual, as the correlation coefficients between the residual and the individual $\eta_{x}$ are small $(|r| \leq 0.26)$. The spread in the residual can thus be understood as a combined effect of small errors arising from each $\eta_{x}$. As such, the spread in the residual does not contradict the main result that models disagree most concerning how their cloud and lower tropical tropospheric temperature and moisture structure changes affect the atmospheric heat budget changes.

The lower tropospheric warming response and its impact on the surface energy budget thus are crucial to better understand how the atmospheric heat budget and therefore precipitation will change on slow time scales. Moreover, this understanding seems to also be important to interpret the offset in ensemble-mean $\eta$ between the coupled and noncoupled simulations (section 6).

\section{c. Spread in the adjustment}

Better understanding of the precipitation adjustments $A$ has received less attention than $\eta$. Recently Richardson et al. (2015) have explored regional precipitation adjustments to different forcing agents, where precipitation increases rapidly over land in the tropics but reduces over land in the midlatitudes and over the ocean in response to increased $\mathrm{CO}_{2}$. Here we investigate how the global precipitation adjustment is composed of the separate contributions from the typical factors considered in kernel analyses of radiative effects.

It is straightforward to employ the kernel method to attain these contributions to fast changes of the atmospheric energy budget. Here the radiative contributions to the adjustment are given by the $y$ intercept of the regression. Global-mean precipitation initially decreases (with a median of $A=-4.26 \mathrm{~W} \mathrm{~m}^{-2}$ ) when $\mathrm{CO}_{2}$ increases. This precipitation decrease is sustained by the combined radiative heating of $\mathrm{CO}_{2}$ and the fast cooling of the stratosphere $\left(A_{\mathrm{CO}_{2}+\text { Strat }}=3.67 \mathrm{~W} \mathrm{~m}^{-2}\right)$, which induces additional atmospheric heating (Fig. 7).

The decomposition shows that precipitation adjustments are not influenced by the surface albedo or by the Planck effect (medians of $A_{\text {Albedo }}=0.01 \mathrm{~W} \mathrm{~m}^{-2}$ and $\left.A_{\text {Planck }}=0.01 \mathrm{~W} \mathrm{~m}^{-2}\right)$, nor does water vapor have a discernible effect $\left(A_{\mathrm{WV}}=0.13 \mathrm{~W} \mathrm{~m}^{-2}\right)$. The only other term systematically influencing the fast changes of the atmospheric heat budget appears to be the lapse-rate adjustment $\left(A_{\mathrm{LR}}=-1.34 \mathrm{~W} \mathrm{~m}^{-2}\right)$. The lapse-rate

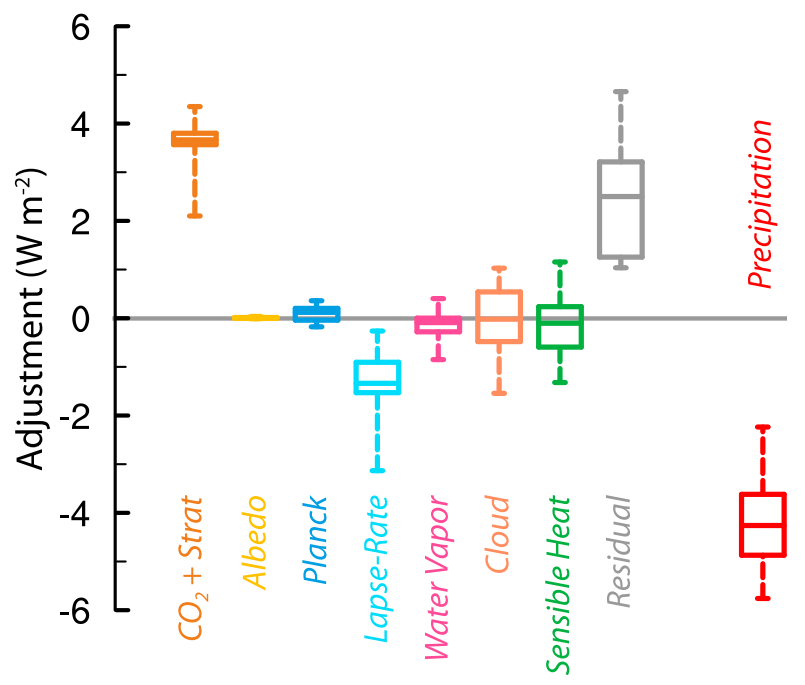

FIG. 7. Decomposition of the atmospheric heat budget adjustment derived from 26 models performing the abrupt4xCO2 experiment. More details are provided in the caption of Fig. 6.

adjustment influences the hydrological cycle through stabilizing the atmosphere (Kamae et al. 2015). The stabilization of the atmosphere with higher $\mathrm{CO}_{2}$ levels increases atmospheric cooling and thus counteracts the direct effect of $\mathrm{CO}_{2}$ on the precipitation adjustment. Our analysis reveals a considerable intermodel spread in the lapse rate and cloud adjustment.

It is somewhat discouraging that not only does the residual exhibit a large spread, but the residual is also large with a median of $2.50 \mathrm{~W} \mathrm{~m}^{-2}$. The reason for this offset in the radiative decomposition of the adjustment is difficult to trace down; we tested for two possible errors arising from estimating the adjustment via the regression method. Residuals in the adjustment may result from nonlinearities in any of the $\Delta R_{x}$ with $\Delta T_{s}$, or from the fact that the regression-based adjustment does not capture internal variability. However, neither of these two possible errors can account for the offset in the adjustment residual from the radiative decomposition (see detailed discussion in section S2 of the supplementary material including $A_{x}$ estimated with the fixedSST method).

Studies investigating the $\mathrm{CO}_{2}$ plant physiological effect find differing (about a factor of 4 ) estimates of rapid precipitation reduction over land due to reduced transpiration in two models [Abe et al. (2015) find approximately $-0.75 \mathrm{~W} \mathrm{~m}^{-2}$ in MIROC3 and Andrews et al. (2011) approximately $-2.89 \mathrm{~W} \mathrm{~m}^{-2}$ in HadCM3], which may also be a source for intermodel spread of $A_{x}$ and $A_{\mathrm{SH}}$. The kernel decomposition cannot identify the role of plant physiological effects in the intermodel spread in adjustment; this deficiency cannot explain the 
residual, however, because the radiative fluxes have to balance with or without a plant physiological effect.

Notwithstanding the difficulties in attributing the residual, the sensible heat flux is unaffected by the radiative decomposition and evolves quite linearly with $\Delta T_{S}$, and its adjustment is consistently diagnosed with both calculation methods (see the bottom-left panel of Fig. S2 in the supplementary material). Half of the models predict that the sensible heat flux increases on fast time scales, while the other half predicts the opposite (Fig. 7). Considering that the spread in sensible heat flux adjustment correlates strongly with the spread in fast precipitation adjustment $(r=0.76)$, for future work it would be useful to improve understanding of fast sensible heat flux changes to get a deeper insight in fast precipitation changes.

In summary, to represent precipitation changes on fast time scales more consistently among models, more understanding about the spread in fast adjustment to a $\mathrm{CO}_{2}$ forcing is required. In particular, our results have shown that more attention is needed to better separate radiative contributions to the adjustment from vertical temperature structure changes and sensible heat flux changes immediately after $\mathrm{CO}_{2}$ levels have been raised.

\section{Hydrological sensitivity parameter in coupled versus noncoupled experiments}

The magnitude of the estimated $\eta$ between coupled ocean-atmosphere and noncoupled atmosphere-only models differs surprisingly by approximately $12 \%-$ $30 \%$ (section 3 ), although intermodel spread in $\eta$ is similarly small (dispersion of $10.7 \%$ and $9.3 \%$ for the coupled abrupt4xCO2 experiment and for the noncoupled amip4K experiment). As a first assumption we expected the same magnitude of $\eta$ in both the coupled and noncoupled experiment. If $\eta$ is a consistent descriptive quantity of the climate system, constrained by the atmospheric heat budget, $\eta$ should be of the same magnitude independent of the model configuration. Although the noncoupled amip experiments do not account for changes in ocean temperatures in response to surface flux imbalances, they have the advantage of being driven by observed sea surface temperature distributions and thus more adequately represent the pattern of precipitation. Here we discuss possible reasons for a larger $\eta$ in the noncoupled model configuration.

Differing magnitudes in $\eta$ can easily be achieved by employing either the endpoint or regression method (Table 3). This reasoning does not apply here because the hydrological sensitivity parameter is concisely defined as the slope of precipitation change with surface temperature change when accounting for the fast precipitation adjustment. The expectation of similar multimodel-mean $\eta$ in different experiments relies on the assumption that the atmospheric heat budgets will change in the same way with warming. In the following we test several hypotheses for why the atmospheric radiative cooling may increase more strongly in the noncoupled models.

The warming patterns differ between the coupled and the amip4K experiments. The coupled abrupt4xCO2 experiment exhibits stronger polar than tropical warming, whereas the sea surface in amip4K per definition warms globally uniformly. We test for the influence of warming patterns by estimating $\eta$ in patterned warming amip experiments (amipFuture), which are scaled to also warm by $4 \mathrm{~K}$ in the global mean. Analysis is performed for a subset of eight available amip4K and amipFuture models. If patterned warming was responsible for the greater $\eta$ in amip4K than in abrupt4xCO2, then $\eta$ would have to be smaller in amipFuture. This is, however, not the case as in seven of eight models $\eta$ is even slightly larger (not shown). Patterned warming is thus not the reason for higher mean $\eta$ in the noncoupled model configuration.

The hydrological sensitivity parameter may be lower in a higher $\mathrm{CO}_{2}$ loading world (Good et al. 2012). Is the lower $\mathrm{CO}_{2}$ concentration in amip4K causing the higher $\eta$ ? We address this suggestion by performing amip and amip4k experiments at $4 \times \mathrm{CO}_{2}$ concentrations in the ECHAM6 model (Stevens et al. 2013). Indeed, we find that $\eta$ is smaller by $6 \%$ compared to the corresponding ECHAM amip4K experiment at $1 \times \mathrm{CO}_{2}$ concentration (2.63 versus $2.79 \mathrm{~W} \mathrm{~m}^{-2} \mathrm{~K}^{-1}$ ). This finding, however, accounts for less than one-third of the difference in $\eta$ between the coupled $\left(2.15 \mathrm{~W} \mathrm{~m}^{-2} \mathrm{~K}^{-1}\right)$ and noncoupled (2.74 $\mathrm{W} \mathrm{m}^{-2} \mathrm{~K}^{-1}$ ) MPI-ESM-LR model.

Finally, we investigate how the atmospheric heat budget is influenced by differently changing state variables like temperature, humidity, or clouds between the coupled and noncoupled models. For this, we perform the same kernel methodology as in section $5 \mathrm{~b}$ to the time-mean differences of amip4K and amipFuture respectively. Only six models are included in this analysis, as not all necessary variables were available for BCC_ CSM1.1 and IPSL-CM5B-LR.

The greatest offset between coupled and noncoupled models is found in how the thermodynamic structure changes (Fig. 8). A systematic difference in radiative impact of cloud changes between coupled and noncoupled experiments is apparent, but this difference actually counteracts the signal of higher $\eta$ in noncoupled models. The offset in changes in the thermodynamic structure is again dominated by the lower troposphere (pressure $p>700 \mathrm{hPa}$ ), as it warms more strongly in the 


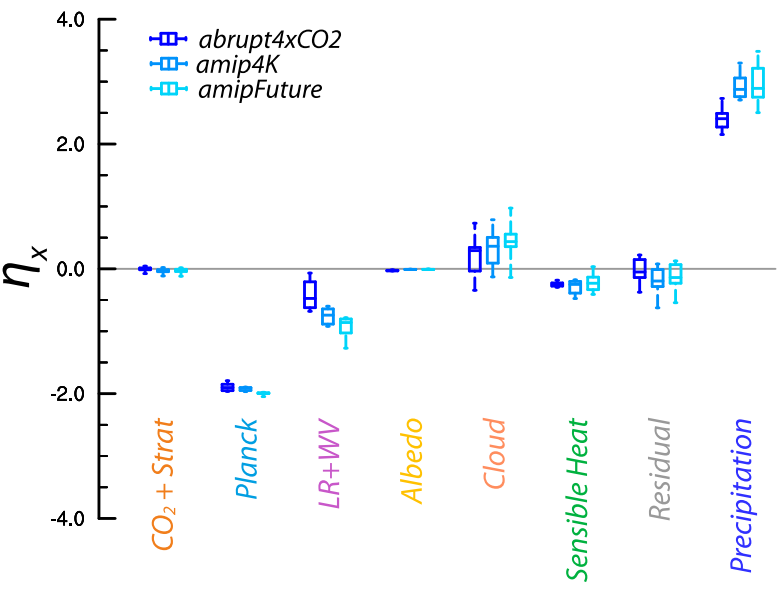

FIG. 8. Comparison of the decomposed $\eta$ between coupled (abrupt4xCO2) and noncoupled (amip4K and amipFuture) experiments. Analysis is performed analogously to Fig. 6a, but for a common set of eight available coupled and noncoupled models.

noncoupled experiments (not shown). A stronger warming implies enhanced atmospheric cooling, and thus a larger hydrological sensitivity parameter. Yet it is unclear how coupling leads to weaker warming in the lower troposphere in abrupt $4 \mathrm{xCO} 2$. Possibly different land-sea contrasts or the fact that the surface temperature cannot respond to precipitation in the noncoupled experiments could offset $\eta$. In any case, the budget analysis suggests that quantifying the effect of coupling on the lower tropospheric thermodynamic structure may provide insights for how precipitation is simulated to change with warming.

Considering that coupling varies the mean values of $\eta$ by $12 \%-30 \%$, it is questionable whether models fully represent the whole scope of the real world hydrological sensitivity parameter. Although the intermodel spread of $\eta$ is small for either the coupled or the noncoupled experiments, the model configuration dictates with which magnitude the atmospheric heat budget adapts to surface warming.

\section{Conclusions}

The majority of previous literature states that models disagree about the slope of precipitation change with respect to surface temperature change with up to a factor of 3 difference between the lowest and highest estimate (Held and Soden 2006; Previdi 2010; O'Gorman et al. 2012). However, the very definition of the slope varies among the studies. To facilitate the comparison of estimates, we introduce a more formal terminology analogous to that of the equilibrium climate sensitivity framework. The slope of temperature-dependent precipitation change, when accounting for rapid precipitation changes (adjustment) of the atmosphere to radiative forcings, is referred to as hydrological sensitivity parameter $\eta$ and the slope of total precipitation response to surface warming as apparent hydrological sensitivity parameter $\eta_{a}$. The word "apparent" encompasses the fact that $\eta_{a}$ depends on atmospheric forcing and surface warming. We introduce the term equilibrium hydrological sensitivity as the equilibrium change of precipitation due to a doubling of $\mathrm{CO}_{2}$.

We compare the intermodel spread and magnitude of $\eta$ and $\eta_{a}$ in four different forcing experiments among current CMIP5 models. We show that intermodel spread in $\eta$ is small in the abrupt $4 \mathrm{xCO} 2$ experiment relative to most previous work. Our estimate of $\eta=2.24 \pm 0.24 \mathrm{~W} \mathrm{~m}^{-2} \mathrm{~K}^{-1}$, with a total range of $1.85-2.73 \mathrm{~W} \mathrm{~m}^{-2} \mathrm{~K}^{-1}$, corresponds to the estimates in Andrews et al. (2009). The spread is larger in part of the other studies because for the definition of $\eta_{a}$ the spread in the adjustment projects onto that of the temperaturedependent precipitation response (Held and Soden 2006; Previdi 2010; Pendergrass and Hartmann 2014). In other studies (Takahashi 2009; Lambert and Allen 2009; Frieler et al. 2011) the multiregression approach to estimate $\eta$ from transient experiments yielded larger spread than the direct calculation from idealized steplike climate change experiments as in this study. We further demonstrate that $\eta$ and $A$ estimated from the idealized abrupt $4 \mathrm{xCO} 2$ experiment reproduce the simulated precipitation in the transient 1 pctCO2 simulation well.

The comparison of the similarly idealized coupled ocean-atmosphere abrupt $4 \mathrm{xCO} 2$ and the noncoupled atmosphere-only amip4K simulations reveals that the experimental configuration modifies the magnitude of $\eta$. In both configurations the atmospheric heat budget changes robustly. However, the choice of whether or not the atmosphere is coupled to the ocean offsets the magnitude of $\eta$ estimates by $12 \%-30 \%$ toward higher $\eta$ in the noncoupled amip4K. This offset suggests that the intermodel spread for a given climate change experiment may underestimate the real model spread of the hydrological sensitivity parameter arising from different experiment configurations. To put this in perspective, the difference in multimodel-mean $\eta$ between the amip $4 \mathrm{~K}$ and abrupt $4 \mathrm{xCO} 2$ experiments is nearly as large as the intermodel spread within one of the experiments.

Although the hydrological sensitivity parameter is more robust than assumed from a literature review, the simulated global-mean precipitation response at the end of the abrupt $4 \mathrm{xCO} 2$ simulation remains uncertain. In equilibrium conditions we attribute this spread in equilibrium hydrological sensitivity due to a quadrupling of $\mathrm{CO}_{2}$ foremost to the uncertainty in the corresponding 
equilibrium climate sensitivity. In contrast, in the first half of the simulation $(\sim 70 \mathrm{yr})$ the largest contributor to the spread is uncertainty in the adjustment, followed by the uncertainty in the hydrological sensitivity parameter.

We perform a radiative decomposition of the atmospheric heat budget changes via the kernel method to attribute how radiative effects influence the hydrological sensitivity parameter and the adjustment. The spread in $\eta$ mainly arises from the spread in cloud radiative effects and lapse rate plus water vapor. The spread in lapse rate and water vapor radiative effects across the model ensemble can be attributed to different lower tropospheric temperature and water vapor changes, foremost in the tropics. In terms of spread in the adjustment, a nonnegligible residual from the decomposition hinders a firm conclusion. The analysis reveals, however, that the spread in the fast response of the sensible heat flux, where half of the models reduce and half increase the sensible heat flux on fast time scales, may be a strong suspect for causing uncertain fast precipitation changes.

Acknowledgments. We thank three anonymous reviewers for their perceptive and helpful suggestions. We thank Angeline Pendergrass and Timothy Andrews for helpful discussions. Hauke Schmidt is thanked for comments on an earlier version of this manuscript, and Karoline Block for providing the radiative kernels. We thank the coupled modeling groups (Table 2) for providing CMIP5 data, coordinated by the World Climate Research Programme's Working Group on Coupled Modelling. This work was supported by the MaxPlanck-Gesellschaft (MPG), funding through the EUCLIPSE project from the European Union, Seventh Framework Programme (FP7/2007-2013) under Grant Agreement 244067, and computational resources were made available by Deutsches Klimarechenzentrum (DKRZ) through support from Bundesministerium für Bildung und Forschung (BMBF). Primary data and scripts used in the analysis and other supplementary information that may be useful in reproducing the author's work are archived by the Max Planck Institute for Meteorology and can be obtained by contacting publications@mpimet.mpg.de.

\section{REFERENCES}

Abe, M., H. Shiogama, T. Yokohata, S. Emori, and T. Nozawa, 2015: Asymmetric impact of the physiological effect of carbon dioxide on hydrological responses to instantaneous negative and positive CO2 forcing. Climate Dyn., 45, 2181-2192, doi:10.1007/s00382-014-2465-1.

Allen, M. R., and W. J. Ingram, 2002: Constraints on future changes in climate and the hydrologic cycle. Nature, 419, 224-232, doi:10.1038/nature01092.
Andrews, T., P. M. Forster, and J. M. Gregory, 2009: A surface energy perspective on climate change. J. Climate, 22, 25572570, doi:10.1175/2008JCLI2759.1.

,-- O. Boucher, N. Bellouin, and A. Jones, 2010: Precipitation, radiative forcing and global temperature change. Geophys. Res. Lett., 37, L14701, doi:10.1029/2010GL043991.

—, M. Doutriaux-Boucher, O. Boucher, and P. Forster, 2011: A regional and global analysis of carbon dioxide physiological forcing and its impact on climate. Climate Dyn., 36, 783-792, doi:10.1007/s00382-010-0742-1.

Arora, V. K., and Coauthors, 2011: Carbon emission limits required to satisfy future representative concentration pathways of greenhouse gases. Geophys. Res. Lett., 38, L05805, doi:10.1029/2010GL046270.

Bala, G., P. B. Duffy, and K. E. Taylor, 2008: Impact of geoengineering schemes on the global hydrological cycle. Proc. Natl. Acad. Sci. USA, 105, 7664-7669, doi:10.1073/pnas.0711648105.

, K. Caldeira, and R. Nemani, 2010: Fast versus slow response in climate change: Implications for the global hydrological cycle. Climate Dyn., 35, 423-434, doi:10.1007/ s00382-009-0583-y.

Bao, Q., and Coauthors, 2013: The Flexible Global OceanAtmosphere-Land System model, spectral version 2: FGOALS-S2. Adv. Atmos. Sci., 30, 561-576, doi:10.1007/ s00376-012-2113-9.

Barnes, E. A., and R. J. Barnes, 2015: Estimating linear trends: Simple linear regression vs. epoch differences. J. Climate, 28, 9969-9976, doi:10.1175/JCLI-D-15-0032.1.

Bentsen, M., and Coauthors, 2013: The Norwegian Earth System Model, NorESM1-M-Part 1: Description and basic evaluation of the physical climate. Geosci. Model Dev., 6, 687-720, doi:10.5194/gmd-6-687-2013.

Bi, D., and Coauthors, 2013: The ACCESS coupled model: Description, control climate and evaluation. Aust. Meteor. Oceanogr. J., 63, 41-64.

Block, K., and T. Mauritsen, 2013: Forcing and feedback in the MPIESM-LR coupled model under abruptly quadrupled $\mathrm{CO}_{2}$. J. Adv. Model. Earth Syst., 5, 676-691, doi:10.1002/jame.20041.

Boer, G. J., 1993: Climate change and the regulation of the surface moisture and energy budgets. Climate Dyn., 8, 225-239, doi:10.1007/BF00198617.

Bony, S., and J.-L. Dufresne, 2005: Marine boundary layer clouds at the heart of tropical cloud feedback uncertainties in climate models. Geophys. Res. Lett., 32, L20806, doi:10.1029/ 2005 GL023851.

- , and Coauthors, 2006: How well do we understand and evaluate climate change feedback processes? J. Climate, 19, 34453482, doi:10.1175/JCLI3819.1.

—, M. Webb, C. Bretherton, S. Klein, P. Siebesma, G. Tselioudis, and M. Zhang, 2011: CFMIP: Towards a better evaluation and understanding of clouds and cloud feedbacks in CMIP5 models. CLIVAR Exchanges, No. 16, International CLIVAR Project Office, Southampton, United Kingdom, 20-24.

Cess, R. D., and Coauthors, 1990: Intercomparison and interpretation of climate feedback processes in 19 atmospheric general circulation models. J. Geophys. Res., 95 (D10), 16 60116 615, doi:10.1029/JD095iD10p16601.

Charney, J. G., and Coauthors, 1979: Carbon dioxide and climate: A scientific assessment. National Academy of Sciences, 34 pp., doi:10.17226/12181.

Collins, W. J., and Coauthors, 2011: Development and evaluation of an Earth-system model-HadGEM2. Geosci. Model Dev., 4, 1051-1075, doi:10.5194/gmd-4-1051-2011. 
Donner, L. J., and Coauthors, 2011: The dynamical core, physical parameterizations, and basic simulation characteristics of the atmospheric component AM3 of the GFDL global coupled model CM3. J. Climate, 24, 3484-3519, doi:10.1175/ 2011JCLI3955.1.

Dufresne, J.-L., and S. Bony, 2008: An assessment of the primary sources of spread of global warming estimates from coupled atmosphere-ocean models. J. Climate, 21, 5135-5144, doi:10.1175/2008JCLI2239.1.

— , and Coauthors, 2013: Climate change projections using the IPSL-CM5 Earth System Model: From CMIP3 to CMIP5. Climate Dyn., 40, 2123-2165, doi:10.1007/ s00382-012-1636-1.

Dunne, J. P., and Coauthors, 2012: GFDL's ESM2 global coupled climate-carbon Earth system models. Part I: Physical formulation and baseline simulation characteristics. J. Climate, 25, 6646-6665, doi:10.1175/JCLI-D-11-00560.1.

Frieler, K., M. Meinshausen, T. Schneider von Deimling, T. Andrews, and P. Forster, 2011: Changes in global-mean precipitation in response to warming, greenhouse gas forcing and black carbon. Geophys. Res. Lett., 38, L04702, doi:10.1029/ 2010GL045953.

Giorgetta, M. A., and Coauthors, 2013: Climate and carbon cycle changes from 1850 to 2100 in MPI-ESM simulations for the Coupled Model Intercomparison Project phase 5. J. $A d v$. Model. Earth Syst., 5, 572-597, doi:10.1002/jame.20038.

Good, P., W. Ingram, F. Lambert, J. Lowe, J. Gregory, M. Webb, M. Ringer, and P. Wu, 2012: A step-response approach for predicting and understanding non-linear precipitation changes. Climate Dyn., 39, 2789-2803, doi:10.1007/ s00382-012-1571-1.

Gregory, J. M., and Coauthors, 2004: A new method for diagnosing radiative forcing and climate sensitivity. Geophys. Res. Lett., 31, L03205, doi:10.1029/2003GL018747.

Hansen, J., and Coauthors, 2005: Efficacy of climate forcings. J. Geophys. Res., 110, D18104, doi:10.1029/2005JD005776.

Hawkins, E., and R. Sutton, 2009: The potential to narrow uncertainty in regional climate predictions. Bull. Amer. Meteor. Soc., 90, 1095-1107, doi:10.1175/2009BAMS2607.1.

Hegerl, G. C., and Coauthors, 2015: Challenges in quantifying changes in the global water cycle. Bull. Amer. Meteor. Soc., 96, 1097-1115, doi:10.1175/BAMS-D-13-00212.1.

Held, I. M., and B. J. Soden, 2006: Robust responses of the hydrological cycle to global warming. J. Climate, 19, 5686-5698, doi:10.1175/JCLI3990.1.

Hourdin, F., and Coauthors, 2013: LMDZ5B: The atmospheric component of the IPSL climate model with revisited parameterizations for clouds and convection. Climate Dyn., 40, 2193-2222, doi:10.1007/s00382-012-1343-y.

Ji, D., and Coauthors, 2014: Description and basic evaluation of BNU-ESM version 1. Geosci. Model Dev., 7, 2039-2064, doi:10.5194/gmd-7-2039-2014.

Kamae, Y., M. Watanabe, T. Ogura, M. Yoshimori, and H. Shiogama, 2015: Rapid adjustments of cloud and hydrological cycle to increasing $\mathrm{CO}_{2}$ : A review. Curr. Climate Change Rep., 1, 103-113, doi:10.1007/s40641-015-0007-5.

Kvalevåg, M. M., B. H. Samset, and G. Myhre, 2013: Hydrological sensitivity to greenhouse gases and aerosols in a global climate model. Geophys. Res. Lett., 40, 1432-1438, doi:10.1002/ $\operatorname{grl} .50318$.

Lambert, F. H., and M. J. Webb, 2008: Dependency of global mean precipitation on surface temperature. Geophys. Res. Lett., 35, L16706, doi:10.1029/2008GL034838.
— and M. R. Allen, 2009: Are changes in global precipitation constrained by the tropospheric energy budget? J. Climate, 22, 499-517, doi:10.1175/2008JCLI2135.1.

Li, L., and Coauthors, 2013: The Flexible Global OceanAtmosphere-Land System Model, grid-point version 2: FGOALS-g2. Adv. Atmos. Sci., 30, 543-560, doi:10.1007/ s00376-012-2140-6.

Meehl, G. A., and Coauthors, 2012: Climate system response to external forcings and climate change projections in CCSM4. J. Climate, 25, 3661-3683, doi:10.1175/JCLI-D-11-00240.1.

Mitchell, J., C. Wilson, and W. Cunnington, 1987: On $\mathrm{CO}_{2}$ climate sensitivity and model dependence of results. Quart. J. Roy. Meteor. Soc., 113, 293-322, doi:10.1002/qj.49711347517.

Newell, R. E., G. F. Herman, S. Gould-Stewart, and M. Tanaka, 1975: Decreased global rainfall during the past ice age. Nature, 253, 33-34, doi:10.1038/253033b0.

O'Gorman, P. A., R. P. Allan, M. P. Byrne, and M. Previdi, 2012: Energetic constraints on precipitation under climate change. Surv. Geophys., 33, 585-608, doi:10.1007/s10712-011-9159-6.

Pendergrass, A. G., and D. L. Hartmann, 2012: Global-mean precipitation and black carbon in AR4 simulations. Geophys. Res. Lett., 39, L01703, doi:10.1029/2011GL050067.

- and - 2014: The atmospheric energy constraint on globalmean precipitation change. J. Climate, 27, 757-768, doi:10.1175/JCLI-D-13-00163.1.

Previdi, M., 2010: Radiative feedbacks on global precipitation. Environ. Res. Lett., 5, 025211, doi:10.1088/1748-9326/5/2/025211.

Ramanathan, V., 1981: The role of ocean-atmosphere interactions in the $\mathrm{CO}_{2}$ climate problem. J. Atmos. Sci., 38, 918-930, doi:10.1175/1520-0469(1981)038<0918:TROOAI >2.0.CO;2.

Richardson, T. B., P. M. Forster, D. J. Parker, and T. Andrews, 2015: Understanding the rapid precipitation response to $\mathrm{CO}_{2}$ and aerosol forcing on a regional scale. J. Climate, doi:10.1175/ JCLI-D-15-0174.1, in press.

Rotstayn, L. D., S. J. Jeffrey, M. A. Collier, S. M. Dravitzki, A. C. Hirst, J. I. Syktus, and K. K. Wong, 2012: Aerosol- and greenhouse gas-induced changes in summer rainfall and circulation in the Australasian region: A study using singleforcing climate simulations. Atmos. Chem. Phys., 12, 63776404, doi:10.5194/acp-12-6377-2012.

Schmidt, G. A., and Coauthors, 2014: Configuration and assessment of the GISS ModelE2 contributions to the CMIP5 archive. J. Adv. Model. Earth Syst., 6, 141-184, doi:10.1002/ 2013MS000265.

Sherwood, S. C., S. Bony, O. Boucher, C. Bretherton, P. M. Forster, J. M. Gregory, and B. Stevens, 2015: Adjustments in the forcing-feedback framework for understanding climate change. Bull. Amer. Meteor. Soc., 96, 217-228, doi:10.1175/ BAMS-D-13-00167.1.

Soden, B. J., I. M. Held, R. Colman, K. M. Shell, J. T. Kiehl, and C. A. Shields, 2008: Quantifying climate feedbacks using radiative kernels. J. Climate, 21, 3504-3520, doi:10.1175/ 2007JCLI2110.1.

Stevens, B., 2015: Rethinking the lower bound on aerosol radiative forcing. J. Climate, 28, 4794-4819, doi:10.1175/ JCLI-D-14-00656.1.

- and Coauthors, 2013: Atmospheric component of the MPI-M Earth System Model: ECHAM6. J. Adv. Model. Earth Syst., 5, 146-172, doi:10.1002/jame.20015.

Takahashi, K., 2009: The global hydrological cycle and atmospheric shortwave absorption in climate models under $\mathrm{CO}_{2}$ forcing. J. Climate, 22, 5667-5675, doi:10.1175/ 2009JCLI2674.1. 
Taylor, K. E., R. J. Stouffer, and G. A. Meehl, 2012: An overview of CMIP5 and the experiment design. Bull. Amer. Meteor. Soc., 93, 485-498, doi:10.1175/BAMS-D-11-00094.1.

Thorpe, L., and T. Andrews, 2014: The physical drivers of historical and 21st century global precipitation changes. Environ. Res. Lett., 9, 064024, doi:10.1088/1748-9326/9/6/064024.

Trenberth, K., J. Fasullo, and L. Smith, 2005: Trends and variability in column-integrated atmospheric water vapor. Climate Dyn. 24, 741-758, doi:10.1007/s00382-005-0017-4.

Vial, J., J.-L. Dufresne, and S. Bony, 2013: On the interpretation of inter-model spread in CMIP5 climate sensitivity estimates. Climate Dyn., 41, 3339-3362, doi:10.1007/s00382-013-1725-9.

Voldoire, A., and Coauthors, 2013: The CNRM-CM5.1 global climate model: Description and basic evaluation. Climate Dyn., 40, 2091-2121, doi:10.1007/s00382-011-1259-y.

Volodin, E. M., N. A. Dianskii, and A. V. Gusev, 2010: Simulating present-day climate with the INMCM4.0 coupled model of the atmospheric and oceanic general circulations. Izv. Atmos. Ocean. Phys., 46, 414-431, doi:10.1134/S000143381004002X.

von Salzen, K., and Coauthors, 2013: The Canadian Fourth Generation Atmospheric Global Climate Model (CanAM4). Part
I: Representation of physical processes. Atmos.-Ocean, 51, 104-125, doi:10.1080/07055900.2012.755610.

Watanabe, M., and Coauthors, 2010: Improved climate simulation by MIROC5: Mean states, variability, and climate sensitivity. J. Climate, 23, 6312-6335, doi:10.1175/2010JCLI3679.1.

Watanabe, S., and Coauthors, 2011: MIROC-ESM 2010: Model description and basic results of CMIP5-20c3m experiments. Geosci. Model Dev., 4, 845-872, doi:10.5194/ gmd-4-845-2011.

Wu, T., and Coauthors, 2014: An overview of BCC climate system model development and application for climate change studies. J. Meteor. Res., 28, 34-56, doi:10.1007/ s13351-014-3041-7.

Yukimoto, S., and Coauthors, 2012: A new global climate model of the Meteorological Research Institute: MRI-CGCM3 - Model description and basic performance. J. Meteor. Soc. Japan, 90A, 23-64, doi:10.2151/jmsj.2012-A02.

Zelinka, M. D., S. A. Klein, and D. L. Hartmann, 2012: Computing and partitioning cloud feedbacks using cloud property histograms. Part I: Cloud radiative kernels. J. Climate, 25, 37153735, doi:10.1175/JCLI-D-11-00248.1. 